Manuscript published in Archaeological and Anthropological Sciences 2018

\title{
Copper metallurgy in prehistoric upper Ili Valley, Xinjiang, China
}

Lu Wang ${ }^{1}$, Fan Chen ${ }^{2}$, Yongqiang Wang ${ }^{3}$, Wei Qian ${ }^{1}$, Jianjun Mei ${ }^{1,4}$, Marcos Martinón-Torres ${ }^{5}$, Kunlong Chen ${ }^{1,5}$

${ }^{1}$ Institute of Cultural Heritage and History of Science \& Technology, University of Science and Technology Beijing, Beijing 100083, China

2 School of Chinese Classic, Renmin University, Beijing 100872, China

${ }^{3}$ Xinjiang Institute of Archaeology and Cultural Relics, Urumqi 830011, China

${ }^{4}$ Needham Research Institute, Cambridge CB3 9AF, UK

${ }^{5}$ UCL Institute of Archaeology, London WC1H OPY, UK

\begin{abstract}
The upper Ili Valley in northwest Xinjiang is a crucial place for the study of early interactions between the Eurasian Steppe and northern China. This paper presents scientific analytical results and examines the use and production of copper alloys in the region with regard to the transregional exchange of materials and technology. The substantial proportion of unalloyed copper and clear drop in tin concentrations in the bronze samples from the Iron Age indicates the decrease of tin usage compared with the Bronze Age. The shift between the Bronze and Iron Ages can also be seen from the lead isotope results. The changes of the material (alloys) and metal source(s) between the Bronze and Iron Ages in the upper Ili Valley imply movements of objects, raw materials and related technical practises.
\end{abstract}

\section{KEYWORDS}

Early metallurgy; Copper/bronze; Lead isotope; Technological diffusion; Upper Ili Valley

\section{ELECTRONIC SUPPLEMENTARY MATERIAL}

The online version of this article (https://doi.org/10.1007/s12520-018-0679-6) contains supplementary material, which is available to authorized users. 


\section{Introduction}

The early use and production of metal artefacts have been widely quoted as one of key pieces of evidence indicating China's involvement in a prehistoric transcontinental interaction network across Eurasia (e.g., Fitzgerald-Huber 1995; Sherratt 2006; Jaang 2015). In the vast territory spanning from the Urals to the Yellow River, Xinjiang is of particular interest given its intermediate position in eastern Eurasia. The mountainous routes of the Tianshan range were bridges for east-west interaction millennia before the Silk Roads were historically documented (e.g., Mei 2000; Linduff 2004; Millward 2007; Frachetti et al. 2017). The Ili River Valley in northwest Xinjiang was one such major artery for early interactions.

The Ili River originates in the middle of the Tianshan mountain range and flows westward into the Lake Balkhash. Its mainstream and principle tributaries, namely the Kax, Künes and Tekes rivers irrigate the rugged and mountainous upper Ili Valley (UIV) region, which forms the major part of present-day Ili Kazakh Autonomous Prefecture in northwest Xinjiang, China (Fig. 1). The contiguous mountain systems of the Tianshan range separate the UIV region from the Dzungarian and Tarim basins in the north and south respectively, and also obstruct dry/hot currents of air from the deserts and dry/cold ones from Siberia. This topographic setting forms a humid and temperate climate in the UIV that has nurtured the development of human societies for thousands of years (Xu et al. 2011; Wang et al. 2015).

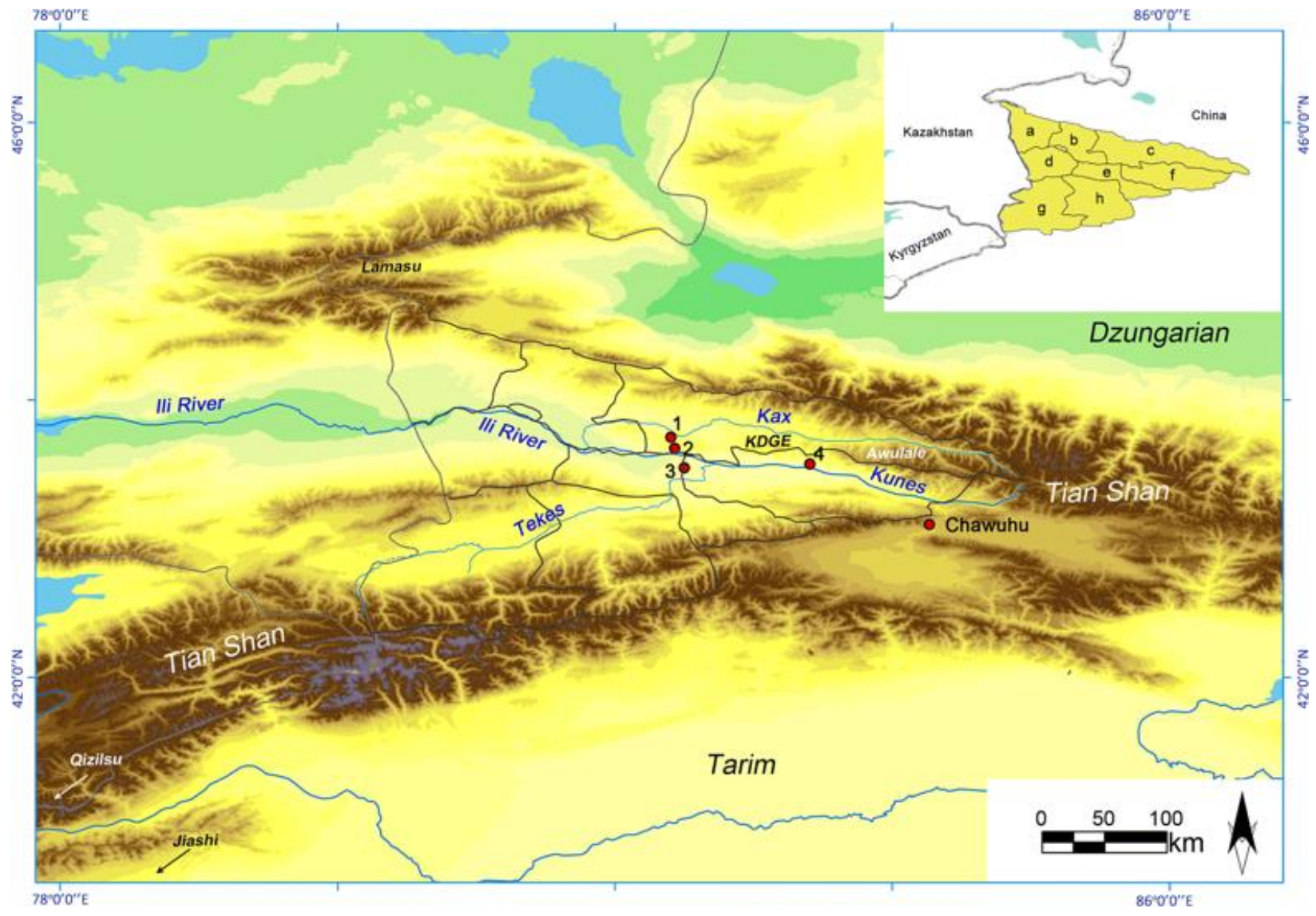




\section{Fig. 1}

Map of the upper Ili Valley region showing the position of counties and sites mentioned in the text. Counties: a Huocheng. b Yining. c Nileke. d Chaqal. e Gongliu. $\mathbf{f}$ Xinyuan. g Zhaosu. $\mathbf{h}$ Tekes. Sites: $\mathbf{1}$ Nulasai; 2 Yuantoushan; 3 Aga'ersen; 4 Yutang.

Since the 1970s, copper and bronze artefacts dated to the prehistoric period have been reported from the UIV region, including the Aga'ersen hoard in Gongliu, the Yutang (鱼塘, fishpond) cemetery site of No. 1 company, 71 regiment in Xinyuan and many stray finds (e.g., Wang 1987; Wang and Cheng 1989; $\mathrm{Li}$ and Dang 1995). The significance of these finds was immediately realised through comparison with similar artefacts found in Central Asia. The shaft-hole axes, sickles and related items from the Aga'ersen group were associated with the Andronovo complex in Kyrgyzstan and Semirechye in eastern Kazakhstan, and dated to the later part of the second millennium BCE (Wang 1985a, b; Peng 1998); while the cauldrons, square plates and altars were ascribed to the Saka or other pastoralist groups in neighbouring regions (Wang 1985a, b; Chen and Hiebert 1995; Gong 1997). Furthermore, the discovery of mining and smelting remains of the first millennium BCE at Nulasai and Yuantoushan in Nilake county and relevant research work have provided solid evidence for local metallurgical production in late prehistoric Xinjiang (Wang 1985a, b; Wang 1986; Mei and Li 1998).

Recently, further archaeological excavations and research into prehistoric Xinjiang have resulted in remarkable progress toward the establishing of developmental sequence of prehistory cultures (see the reviews by Song 2009; Liu and Li 2012; Marchella et al. 2017). Several monographs have systematically examined the available archaeological evidence within a comprehensive spatial-temporal framework (Han 2007; Shao 2007; Guo 2012). In the UIV region, recent excavations have revealed a number of burial and settlement sites and provided provenanced comparand for many chance finds of metal objects previously known in the region (e.g., Liu and Guan 2002; Ruan 2011; Ruan 2012). Despite the long-running controversy over the periodization of Xinjiang's Bronze Age and Iron Age (Wang 1985a, b; Chen 1987; Lu 1995), it is now generally accepted that the archaeological cultures in the prehistoric UIV region can be broadly divided into two separate phases, namely the Bronze Age and the Iron Age, with the transition taking place in the early first millennium BCE (Mei 2000; Chen 2000; Han 2007). It has also been realised that since the Bronze Age, the valley had been closely connected with the Inner Asia highlands and the steppes further north and west (Frachetti 2012; Mei and Colin 1999).

Since the 1990s, several hundred early copper and bronze objects found in Xinjiang have been investigated and scientifically examined, demonstrating both their typological and technological similarities to those from neighbouring areas, such as the Gansu-Qinghai regions in the east and the steppes in the north and west (e.g., Chen and Hiebert 1995; Mei et al. 1998; Mei and Colin 1999; Mei 2000; Qian 2006; Ling 2008; Mei et al. 2013). It has been argued that Xinjiang may have played an intermediate role in introducing metallurgy from the steppes into northwest China, and further east, eventually reaching the agricultural societies of the middle-lower reaches of the Yellow River (Mei 2000; Li 2005; Hwang 2014). Taking into consideration, Xinjiang's vast territory and diverse archaeological cultures, however, further archaeometallurgical, especially lead isotopic, research is still needed to enhance our understanding of the early use and production of metals in Xinjiang and their relationship with neighbouring regions. This paper, based on the scientific analysis of chemical composition, 
metallography and lead isotopes, examines the use and production of copper alloys in the prehistoric UIV region and discusses related issues, such as the transregional exchange of materials and technology.

\section{Materials and methods}

The copper/bronze artefacts in this research come from the collection of the lli Kazakh Autonomous Prefecture Museum. The whole assemblage of samples is composed of 33 copper/bronze objects covering different typological categories, such as vessels, implements, weaponry and altars/lamps. Two copper ingots were also sampled for this research. It should be pointed out that most of the objects sampled here are chance findings from the UIV regions, especially the counties of Gongliu (Toqquz Tara), Xinyuan (Künes) and Tekes (see Fig. 1); therefore, our understanding of their archaeological background is rather limited. In the light of recent archaeological discoveries and comprehensive typological studies on early metal objects in Xinjiang and neighbouring areas (Ruan 2011, 2013), we are, however, able to differentiate these objects into two different complexes. The shaft-hole and socketed axes, sickles, gouge and single-blade knives (Fig. 2: 1-4) are analogous to the ones from the Aga'ersen hoard.

Therefore, they can be ascribed to the Bronze Age Andronovo horizon, which is dated, in the region of Semirechye, from the middle second to early first millennium BCE (Shao 2007; Yang et al. 2016). The large cauldrons, altars/lamps, ingots and statues (Fig. 2: 5-9) can be assigned to the Iron Age Suodunbulake or Ili Valley archaeological cultures of pastoralist societies such as the Saka people in Inner Asia (Grigor'ev and Ismagil 1997; Guo 1999, 2007, 2012). Supplementary Table S1 provides the collection records, origin and the periodization/dating for all the objects studied. 

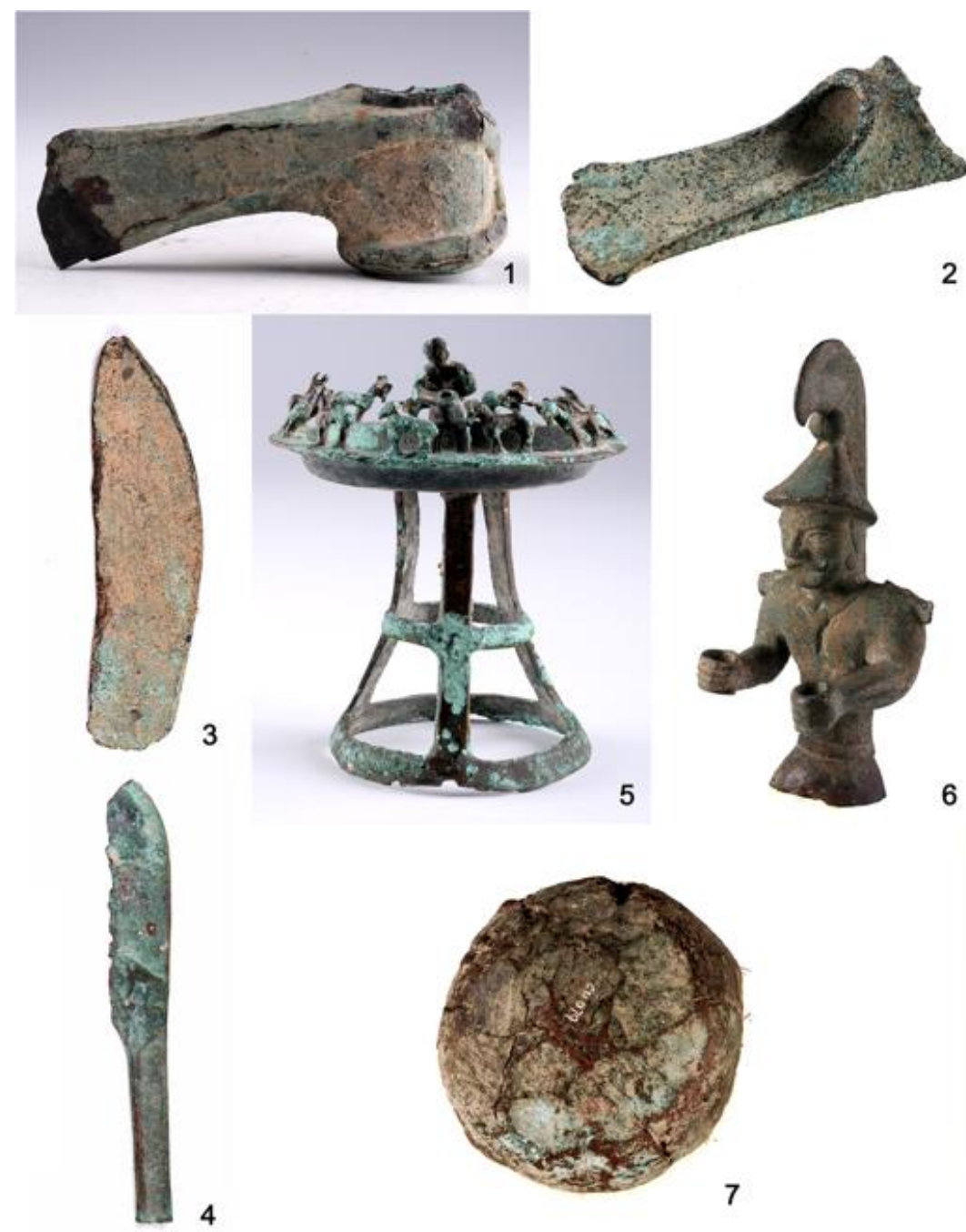

2



6

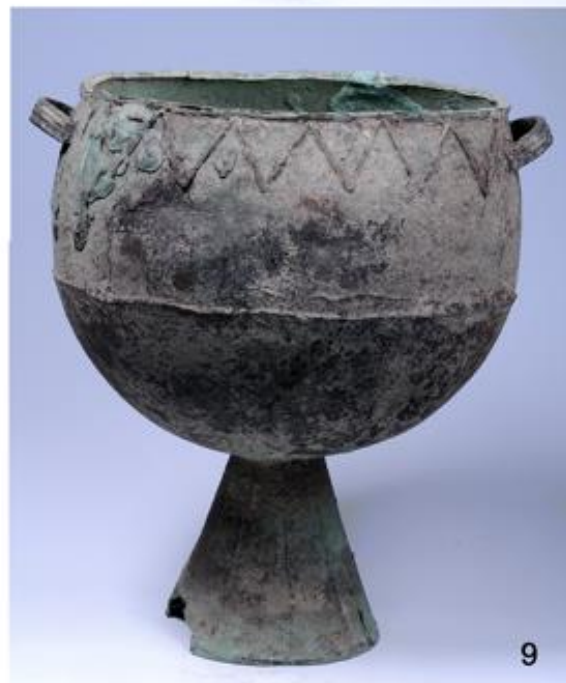

Fig. 2

Examples of prehistoric copper/bronze objects discovered in the lli region. 1 Shaft-hole axe (XY0179); 2 Socketed-axe (XY0489); 3 Sickle (XY0019); 4 Knife (XY0493); 5 Altar/lamp (XY0196); 6 Human statue (XY0173); 7 Ingot (XY0024); 8 Tripod cauldron (XY0477); 9 Circle-footed cauldron (XY0059); (1-4 Bronze Age, 5-9 Iron Age; scales differ, see Supplementary Table S1 for sizes of objects)

In this research, small metal pieces of 24 objects were sawn off from casting seams or broken points for chemical, metallographic and lead isotopic analysis. Patina samples were taken from the surface of a further 9 intact objects for lead isotopic analysis. The metal pieces were mounted in epoxy resin, then ground with sand paper and polished with diamond paste down to $0.5 \mathrm{~mm}$. Metallographic and chemical analyses of the metal samples were conducted with a Leica DM4000M optical microscope and a Zeiss EVO18 scanning electron microscope equipped with a Bruker X-Flash 5010 dispersive spectrum analyser (SEM-EDS) at the University of Science and Technology Beijing (USTB). The analytical conditions of SEM-EDS were set at an acceleration voltage of $20 \mathrm{kV}$, a working distance of $~ 15 \mathrm{~mm}$ and an acquisition time of $60 \mathrm{~s}$. 
Lead isotopes were analysed using a VG Elemental multicollector inductively coupled plasma mass spectrometer (MC-ICP-MS) at Peking University's School of Earth and Space Sciences. Standard material SRM981 was repeated during the analysis, indicating that the overall analytical $2 \delta$ error for all lead isotope ratios was less than $0.04 \%$. Detailed description of methodology and sample preparation procedure for lead isotopic analysis can be found in Cui et al. (2010). Though there is concern that possible contamination from the burial environment may alter the lead isotope composition of the patina in metals with a low-lead content (Gale and Stos-Gale 2000), the results of corrosion from 9 intact objects are retained here as additional data for further comparison and discussion.

\section{Results}

Chemical and lead isotopic ratios of the analysed samples are listed in Table 1 . Although $1 \mathrm{wt} \%$ has been proposed as a potentially more meaningful cutoff value for the classification of archaeological copper alloys (Eaton and McKerrell 1976; Northover 1989; Bray et al. 2015; Pollard et al. 2015), this paper follows the conventional threshold of $2 \mathrm{wt} \%$, which has been widely adopted for Chinese materials to avoid confusion in comparing our results with published data (Wen 1980). According to this criterion, the 24 objects sampled with metal pieces can be divided into two groups, namely unalloyed copper $(\mathrm{Cu}$, 18) and tin bronze (Cu-Sn, 6). This distribution of material types (having both $\mathrm{Cu}$ and $\mathrm{Cu}-\mathrm{Sn}$ ) is consistent with previous studies (Ling et al. 2008). It is worth mentioning that the relatively low levels of lead and arsenic in UIV's objects set them apart from both central China and the Gansu-Qinghai area in terms of typical metal composition. Sulphur, iron and antimony are present in some samples as minor/impurity elements, with the former two being likely correlated with each other. 


\section{Table 1}

Chemical and lead isotopic compositions of copper/bronze objects from the upper lli Valley regions.

\begin{tabular}{|c|c|c|c|c|c|c|c|c|c|c|c|c|c|c|c|c|}
\hline \multirow{2}{*}{ No. } & \multirow{2}{*}{ Objects } & \multirow{2}{*}{ Period } & \multirow{2}{*}{ Origin } & \multicolumn{10}{|c|}{ Chemical composition (SEM-EDS, wt\%) } & \multicolumn{3}{|c|}{ Lead isotope ratios } \\
\hline & & & & $\mathrm{Cu}$ & Sn & As & $\mathrm{Pb}$ & Sb & $\mathrm{Cl}$ & 0 & $\mathbf{S}$ & $\mathrm{Fe}$ & $\mathbf{A g}$ & ${ }^{206} \mathrm{~Pb} /{ }^{204} \mathrm{~Pb}$ & ${ }^{207} \mathrm{~Pb} /{ }^{204} \mathrm{~Pb}$ & ${ }^{208} \mathrm{~Pb} /{ }^{204} \mathrm{~Pb}$ \\
\hline D0013 & Knife & Bronze Age & Tangjiale memorial in Xiinyuan & 83.6 & 15.4 & - & - & - & 0.8 & 0.1 & 0.1 & - & - & 18.126 & 15.562 & 37.975 \\
\hline XY0018 & Socketed axe & Bronze Age & Gongliu County & & & & & / & & & & & & 18.071 & 15.573 & 38.038 \\
\hline XY0019 & Sickle & Bronze Age & Gongliu County & 97.8 & - & 1.0 & - & - & 0.4 & - & 0.7 & 0.1 & - & 18.098 & 15.554 & 37.991 \\
\hline XY0033 & Spear head & Bronze Age & Nileke & & & & & / & & & & & & 18.007 & 15.567 & 38.013 \\
\hline XY0072 & Sickle & Bronze Age & Talede, Xinyuan County & 99.8 & 0.1 & - & - & - & - & - & 0.1 & - & - & 18.613 & 16.075 & 39.381 \\
\hline XY0179 & Shaft-hole axe & Bronze Age & Gongliu County & 79.9 & 7.7 & - & - & - & 2.1 & 9.5 & 0.6 & 0.3 & - & 17.982 & 15.556 & 37.901 \\
\hline XY0488 & Knife & Bronze Age & Qiaolake Tiereke, Tekesi County & 91.0 & 8.3 & - & - & - & 0.1 & 0.3 & 0.2 & 0.1 & - & 18.255 & 15.582 & 38.084 \\
\hline XY0489 & Socketed-axe & Bronze Age & Tekesi County & 91.3 & 8.5 & - & - & - & - & - & 0.1 & 0.1 & - & 17.888 & 15.593 & 37.816 \\
\hline XY0493 & Knife & Bronze Age & Qiaolake Tiereke, Tekesi County & 91.6 & 6.9 & - & - & - & 1.0 & 0.2 & 0.2 & 0.1 & - & 18.377 & 15.800 & 38.679 \\
\hline XY0020 & Chisel & Iron Age & Gongliu County & 91.3 & 2.0 & - & - & 0.1 & 1.0 & 5.4 & 0.2 & - & - & 18.174 & 15.580 & 38.101 \\
\hline XY0024 & Ingot & Iron Age & Wusun mountain, Zhaosu county & 99.6 & - & - & 0.4 & - & - & - & - & - & - & 18.234 & 15.576 & 38.080 \\
\hline XY0027 & Ingot & Iron Age & Central town of Gongliu County & 98.1 & - & - & - & - & - & - & 1.9 & - & - & 18.105 & 15.559 & 38.002 \\
\hline XY0031 & Sward & Iron Age & $\begin{array}{l}\text { Boarder post at Hasang, Zhaosu } \\
\text { County }\end{array}$ & & & & & / & & & & & & 18.147 & 15.568 & 38.026 \\
\hline XY0048 & Sward & Iron Age & Xiaolake Tiereke, Tekesi County & & & & & / & & & & & & 18.260 & 15.582 & 38.106 \\
\hline XY0058 & Altar/lamp & Iron Age & 71 Regiment in Xinyuan County & & & & & / & & & & & & 18.263 & 15.620 & 38.180 \\
\hline XY0059 & Cauldron & Iron Age & 71 Regiment in Xinyuan County & 97.1 & 0.7 & - & - & - & 1.0 & - & 1.1 & 0.1 & - & 18.095 & 15.550 & 37.981 \\
\hline XY0061 & Cauldron & Iron Age & Tasi Bier, Gongliu County & 98.4 & 1.5 & - & 0.2 & - & - & - & - & - & - & 18.108 & 15.554 & 37.993 \\
\hline XY0143 & Altar/lamp & Iron Age & Village 4, Xiata, Zhaosu County & & & & & / & & & & & & 18.478 & 15.646 & 38.374 \\
\hline XY0148 & Cauldron & Iron Age & Subutai, Nileke County & 99.7 & 0.2 & - & - & - & - & - & - & 0.1 & - & 18.345 & 15.683 & 38.562 \\
\hline XY0150 & Cauldron & Iron Age & Tekesi County & 98.3 & 0.5 & 0.4 & 0.3 & 0.2 & - & 0.2 & - & - & - & 18.126 & 15.583 & 37.972 \\
\hline XY0151 & Cauldron & Iron Age & Xinyuan County & 98.9 & 1.0 & - & - & 0.1 & - & - & - & - & - & 18.101 & 15.553 & 37.989 \\
\hline XY0152 & Cauldron & Iron Age & Unknown & 65.3 & 0.2 & - & - & 0.1 & 18.7 & 15.4 & 0.1 & 0.2 & - & 17.677 & 15.562 & 37.978 \\
\hline XY0153 & Cauldron & Iron Age & Mohe, Gongliu County & & & & & / & & & & & & 18.083 & 15.549 & 37.974 \\
\hline XY0156 & Square plate & Iron Age & Mohe, Gongliu County & 99.7 & - & - & - & - & 0.1 & - & - & 0.1 & 0.1 & 18.362 & 15.643 & 38.418 \\
\hline XY0173 & Human statue & Iron Age & Gongliu County & 97.1 & 2.7 & - & - & - & - & - & - & 0.1 & 0.1 & 18.483 & 15.726 & 38.555 \\
\hline
\end{tabular}




\begin{tabular}{|c|c|c|c|c|c|c|c|c|c|c|c|c|c|c|c|c|}
\hline \multirow{2}{*}{ No. } & \multirow{2}{*}{ Objects } & \multirow{2}{*}{ Period } & \multirow{2}{*}{ Origin } & \multicolumn{10}{|c|}{ Chemical composition (SEM-EDS, wt\%) } & \multicolumn{3}{|c|}{ Lead isotope ratios } \\
\hline & & & & $\mathrm{Cu}$ & Sn & As & $\mathrm{Pb}$ & Sb & $\mathrm{Cl}$ & 0 & $\mathbf{S}$ & $\mathrm{Fe}$ & $\mathrm{Ag}$ & ${ }^{206} \mathrm{~Pb} /{ }^{204} \mathrm{~Pb}$ & ${ }^{207} \mathrm{~Pb} /{ }^{204} \mathrm{~Pb}$ & ${ }^{208} \mathrm{~Pb} /{ }^{204} \mathrm{~Pb}$ \\
\hline XY0185 & House bite & Iron Age & Dunmaili, Gongliu County & 88.1 & 0.5 & 1.7 & 0.4 & 0.3 & 1.6 & 7.3 & 0.1 & - & - & 18.175 & 15.599 & 38.113 \\
\hline XY0187 & Chisel & Iron Age & Central town of Gongliu County & 97.1 & 1.7 & - & - & - & 0.2 & 0.2 & 0.7 & 0.1 & - & 18.103 & 15.558 & 37.976 \\
\hline XY0195 & Altar/lamp & Iron Age & Nalati, Xinyuan County & & & & & / & & & & & & 18.309 & 15.635 & 38.150 \\
\hline XY0476 & Cauldron & Iron Age & Unknown & 96.4 & 2.2 & 0.6 & 0.4 & - & 0.1 & - & - & - & 0.3 & 18.092 & 15.546 & 37.969 \\
\hline XY0477 & Cauldron & Iron Age & Zhaosu County & 99.2 & 0.3 & - & - & 0.1 & 0.2 & - & - & - & 0.2 & 18.542 & 15.662 & 38.747 \\
\hline XY0478 & Cauldron & Iron Age & Kushitai, Tekesi County & 99.7 & - & - & - & - & - & - & - & - & 0.3 & 18.529 & 15.654 & 38.673 \\
\hline XY0479 & Cauldron & Iron Age & Tekesi County & 99.5 & 0.2 & - & - & - & 0.1 & - & - & - & 0.2 & 18.528 & 15.742 & 38.783 \\
\hline XY0657 & Mirror & Iron Age & Qiongkeke site, Nileke County & & & & & / & & & & & & 18.093 & 15.579 & 38.082 \\
\hline
\end{tabular}

Several micro-areas were analysed in each sample, and the mean value was used as bulk composition in order to balance out the error caused by potential heterogeneity within samples. The results are normalised with oxygen and chlorine contents to indicate the corrosion condition of the samples. "-" means the value is below the detection limitation, "/" means the data are not available 
The lead isotopic ratios (LIR) of the 33 samples ( 24 metal and 9 patina) were measured here ranging from 17.677 to 18.613 for ${ }^{206} \mathrm{~Pb} /{ }^{204} \mathrm{~Pb}$, from 15.546 to 16.075 for ${ }^{207} \mathrm{~Pb} /{ }^{204} \mathrm{~Pb}$ and from 37.816 to 39.381 for ${ }^{208} \mathrm{~Pb} /{ }^{204} \mathrm{~Pb}$. Given that the low-lead concentration of all analysed samples (always less than $0.5 \mathrm{wt} \%$ and mostly below the detection limit), and the fact that the contribution of lead from tin is generally negligible (Gale and Stos-Gale 2000; Molofsky et al. 2014), it is reasonable to consider the lead as an impurity of the copper rather than as a separate material that was deliberately added in. Therefore, the lead isotopic ratios of the objects very likely reflect the signature of their copper source(s). The nonclustered distribution of the patina sample's LIR data suggests lead contamination from the burial environment was not significant, and the data can be used to represent the metals on which the patina was taken.

Metallographic observation shows that most of the cauldron samples have a typical as-cast microstructure of $\alpha$-copper grains with non-metallic inclusions (e.g., $\mathrm{Cu}_{2} \mathrm{O}$ and $\mathrm{Cu}_{2} \mathrm{~S}$ ) as globules and sometimes enrichment of soluble impurities by coring segregation at grain boundaries (Fig. 3a). The disappearance of casting segregation and relatively large grain size of one cauldron sample (XY0059), together with the residual ash on the surface, suggests extensive firing during its usage (Fig. $3 \mathrm{~b}$ ). On the other hand, samples from tools, such as knives and sickles, are often found to have a metallographic structure of hot or/and cold working. The matrix of equiaxial/twin grains and elongated non-metallic inclusions indicates the experience of hot-working and/or cold-working then annealing (Fig. $3 \mathrm{c}$ ), while the presence of grain deformation and slip bands suggests the application of further cold-working (Fig. 3d). 

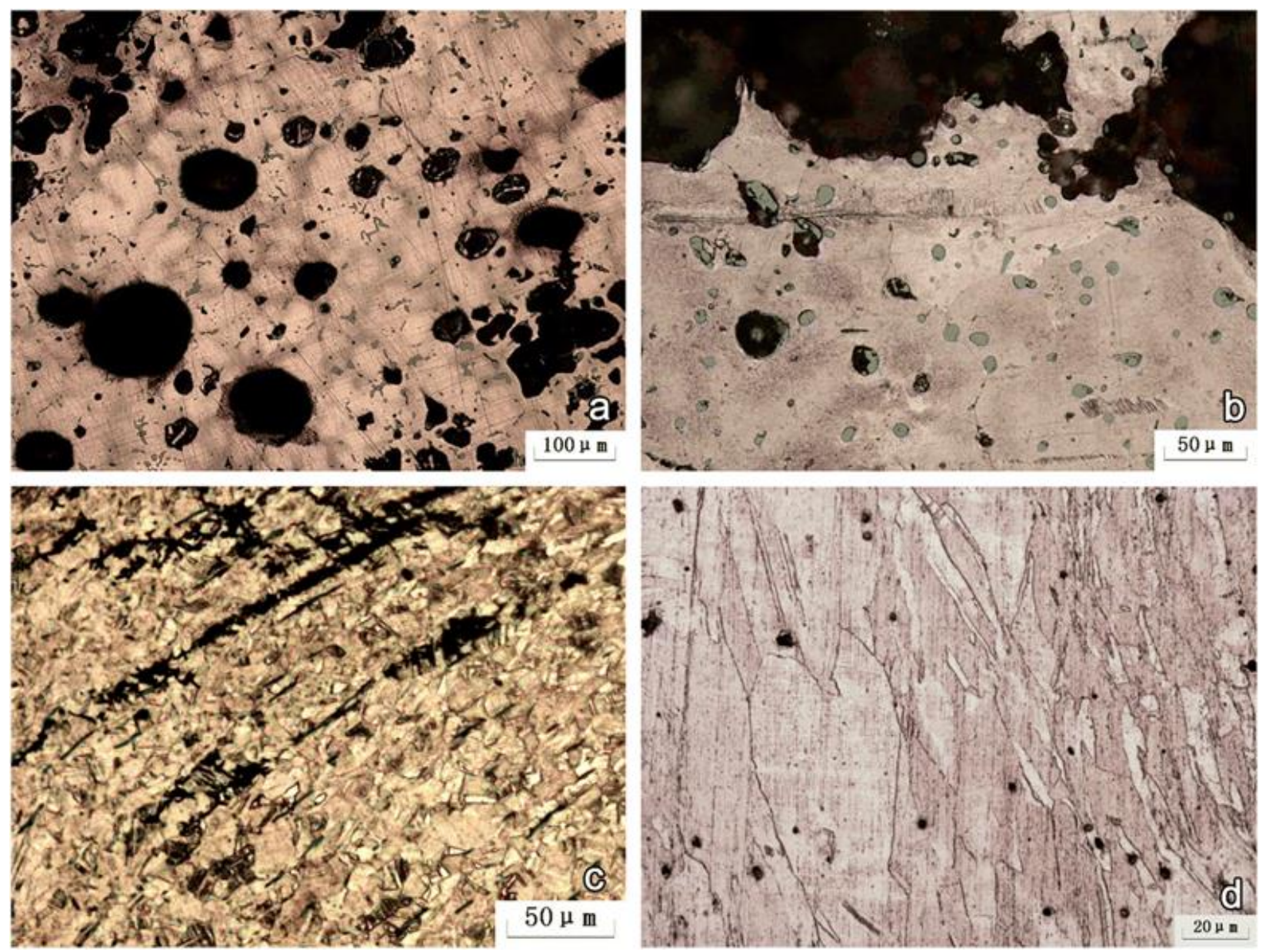

\section{Fig. 3}

Photomicrographs of typical metallographic structures identified among copper/bronze objects from the Ili region. a-b As-cast microstructure of unalloyed copper, noting the abundant porosity (a cauldron XY0476) and occurrence of grey-blue non-metallic inclusions (b cauldron XY0059). c-d Hot/cold worked microstructure of recrystallised equiaxed and twin grains, the aligned and elongated inclusions (c knife XY0488) and grains (d sickle XY0072) are also visible 


\section{Discussion}

\subsection{Shift between the Bronze and Iron Ages}

In his pioneering work, Mei (2000) systemically examined metal objects of prehistoric Xinjiang, emphasising their importance for revealing cultural and technological exchanges across the Eurasian continent. Since then, ongoing archaeological and archaeometallurgical studies have furthered our understanding of the topic considerably (e.g., Qian 2006; Shao 2007; Ling et al. 2008; Guo 2012; Mei et al. 2013; Ruan 2013; Jia et al. 2017). Several important conclusions can now be drawn about Xinjiang's early metallurgy. Firstly, the emergence of the Andronovo complex in northwestern Xinjiang can be traced back to the first part of the second millennium BCE. Metal objects of Andronovo type have been identified in the Ili Valley and neighbouring regions in the western Tianshan, and the relative abundance of tin bronze among the examined objects suggests a technological affinity with bronze cultures of the Eurasian Steppe (Mei and Colin 1999). Secondly, UIV's connection with the steppes, especially with the Semirechye region in eastern Kazakhstan persisted during the Iron Age. Several identical types of objects, such as tripod cauldron, altar/lamp and large square plate, demonstrate the resemblance of metalwork in these regions (Grigor'ev and Ismagil 1997; Guo 2007). Thirdly, it is gradually being recognised that the early copper/bronze metallurgy in northwest Xinjiang, Dzungarian, Tarim and Hami is more diverse in terms of technological practises than previously assumed, for instance, in types of artefacts and materials-and our data add to this diversifying picture. The relationship among the metallurgical traditions of these distinct regions in Xinjiang, and their possible connections to the east with the Hexi Corridor, remains obscure.

The analytical results reported in the present paper show that in the UIV, tin bronze is the major material that was used for tools/weapons during the Bronze Age, while the material for casting the Iron Age cauldrons is mainly unalloyed copper. These results are consistent with the published data from this region (Ling et al. 2008; Mei et al. 2003; Mei et al. 2005). Taking chronology into account, however, an interesting trend emerges, that is the proportion of tin bronze decreased markedly from the Bronze Age to the Iron Age. Although the currently available data are relatively limited, this shift is even more notable when we compare only the tin concentration of tools/weapons that is available for both periods. While the tin concentration of most of the Bronze Age samples exceeds $6 \%$, with an average of $6.7 \%$, the Iron Age samples have much lower tin, all less than $3 \%$ and around $1.4 \%$ on average (Table 1). This trend implies a potential shortage of tin supply in Iron Age UIV, which seems to agree with the situation in Cis-Baikal and Tuva noticed by Hsu et al. (2016).

The shift between the Bronze Age and the Iron Age can also be seen from the lead isotope results. In Fig. 4, lead isotopic data are presented in scatter plots split by chronological periods. They show that most of the Iron Age samples are clustered together with ${ }^{206} \mathrm{~Pb} /{ }^{204} \mathrm{~Pb}$ ratios of $18.1 \sim 18.4$ and ${ }^{207} \mathrm{~Pb} /{ }^{206} \mathrm{~Pb}$ ratios of $0.85 \sim 0.86$. Despite the overlaps in both diagrams, 6 out of 9 Bronze Age samples can be separated from the Iron Age ones with lower ${ }^{208} \mathrm{~Pb} /{ }^{206} \mathrm{~Pb}$ or higher ${ }^{206} \mathrm{~Pb} /{ }^{204} \mathrm{~Pb}$ ratios, implying that the copper resource(s) for the Bronze Age were likely different from those used in Iron Age UIV. 

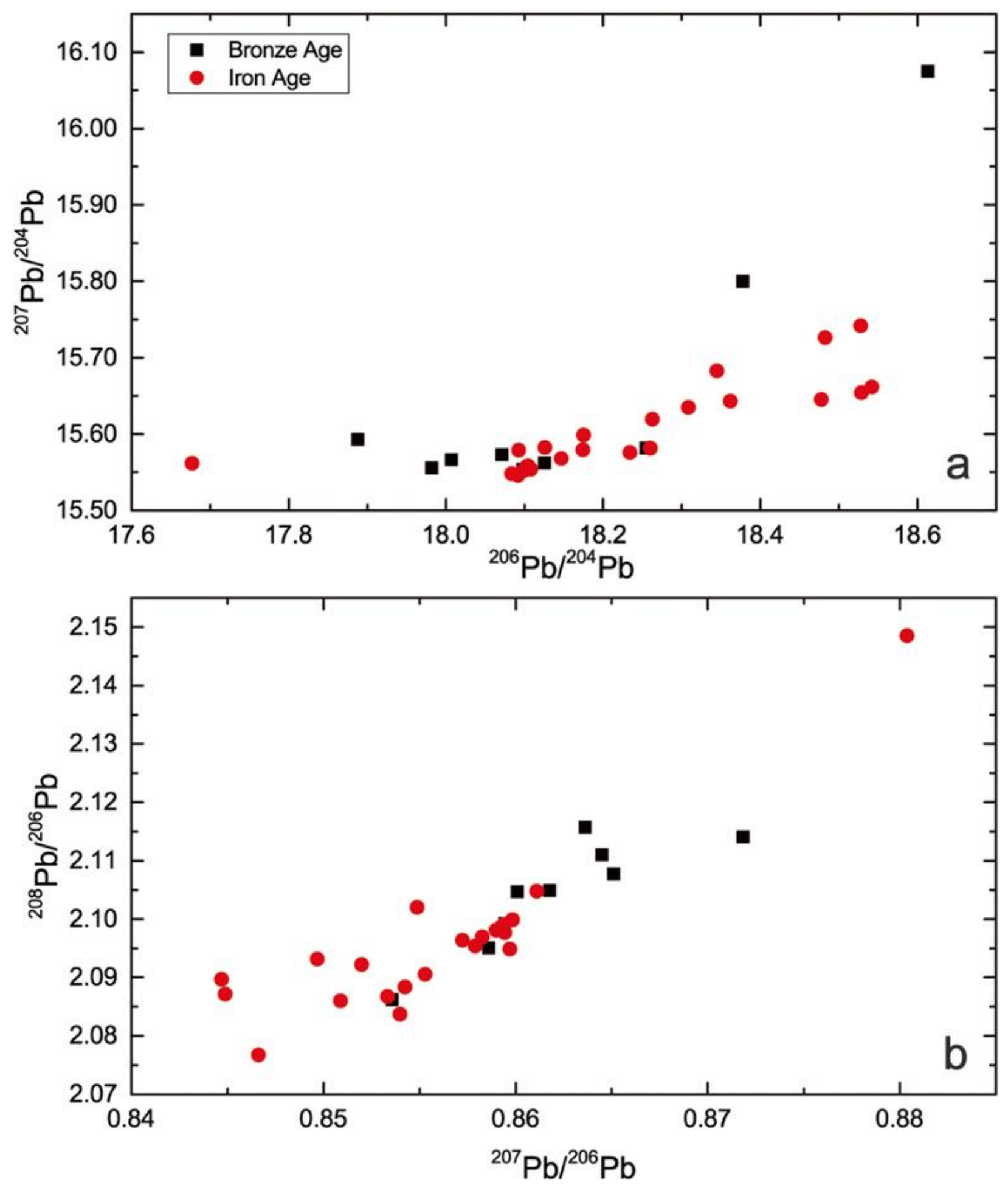

Fig. 4

Plots of lead isotope ratios of copper/bronze objects from the lli region 


\subsection{Localised metallurgy in the upper Ili Valley}

The differences in chemical and lead isotopic composition indicate some changes in the technological practises and supply of raw materials for the copper/bronze objects found in the UIV between the Bronze and Iron Ages. One plausible explanation for these changes could be the localisation of metallurgy in the UIV during this transition. While copper deposits along the Awulale and other mineralisation belts in the middle and northern part of the valley may have been potential sources available to ancient inhabitants (e.g., Chen 2003; Ma et al. 2017), the identification of ancient mining/smelting sites at Nulasai and Yuantoushan in Nileke County provides concrete evidence for local metallurgical production in the region (Wang 1984; Wang 1985a, b).

Yuantoushan was reported as a mining site with an absence of technological remains relating to smelting activities, and dated to cal 1191-236 BCE (BK77001, 95.4\% probability, curve: IntCal 13) by carbon dating of a charcoal sample (Wang 1985a, b; IoA, CASS 1992). We visited the site in summer 2016 and identified one stone hammer despite of a serious damage resulting from modern mining in the area (Fig. 5). At the Nulasai site, more than a dozen ancient mining shafts and smelting slag heaps, from which five "matte ingots" were unearthed, have been recorded (Wang 1984, 1985a, b). A pit timber from the mining shaft at Nulasai was radiocarbon dated to cal 752-206 BCE (WB82-51, 95.4\% probability, curve: IntCal 13) (IoA, CASS 1992). Mei and Li (1998) suggested a relatively sophisticated technical flowchart for Nulasai's smelting process based on examination of the ore and slag samples: plumbiferous copper sulphide ores were roasted first, the subsequent smelting producing lower-grade matte; the matte was then roasted and arsenious ores were added to for the second smelting, which resulted in arsenic-containing higher-grade matte; the resulting matte was further roasted and smelted, yielding a product of $\mathrm{Cu}-\mathrm{As}-\mathrm{Pb}$ alloys. 


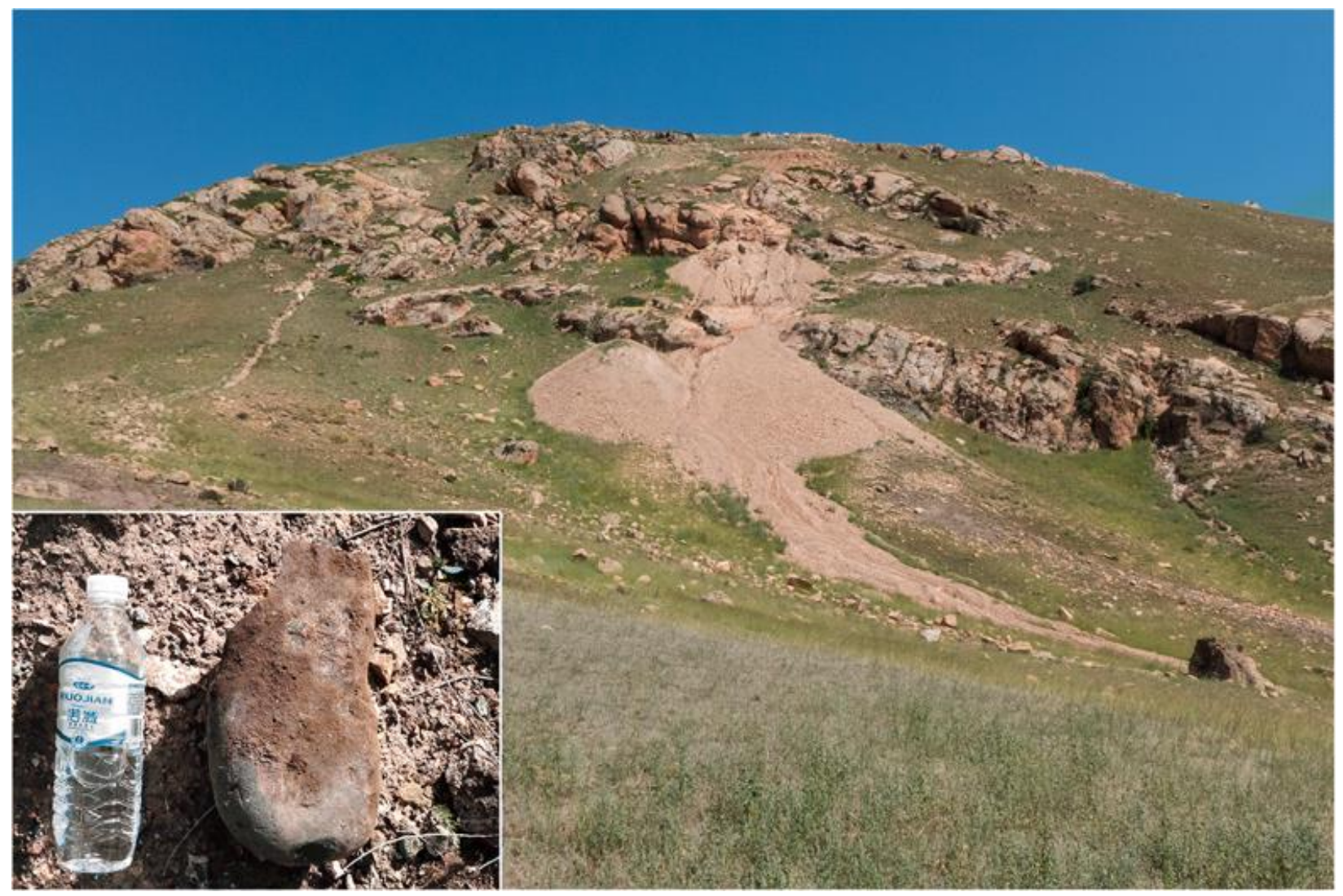

Fig. 5

Modern mining trench and ancient stone hammer found at the site of Yuantoushan (photo taken in 2016)

To assess the relationship between the metal objects and local metallurgical practises in the UIV, published lead isotope data for copper mines in the relevant regions together with slag from the Nulasai site and ingots discovered in various places within the UIV were collected for comparison with the data generated by this research. The results show that the lead isotope ratios of two copper deposit belts in the Ili region, Awulale (including Yuantoushan and Nulasai mines) and Kedenggaoer, cluster together in a relatively narrow area and are distinguished from the others, although the occurrence of outlying data is also notable (Fig. 6a). Most of the data for the ancient slag from Nulasai and ingots fall in the distribution region of the lli mines; in particular, the data for the slag samples and one ingot (No. 121) are almost identical, strongly indicating a common origin and defining the data distribution of local metallurgical production at Nulasai (Fig. 6b). There is one Bronze Age sickle (XY0019) that overlaps with the Nulasai slag together with two others (XY0018 and D0013, see Table 1 and Supplementary Table S1) close to it, but the rest are notably different (Fig. 6c). On the other hand, half of the Iron Age samples cluster together in the distribution region of the Awulale deposit belt, and the data of six of these samples cannot be differentiated from the Nulasai slag, and so are very likely to originate from the Ili ore and local metallurgical production. The other half of the Iron Age samples, having a relatively broad range of lead isotopic ratios, tend to be varied and extraneous (Fig. 6d). 



Fig. 6

Plots of lead isotope ratios of mines in Ili and related region (a), technological remains and ingots discovered in Ili (b) and their relations with analysed objects (c, d). (Slag and ingots samples are all from the Nulasai site except two, XY0024 and XY0027 from this research)

The aforementioned observations are significant for an understanding of the flow of material/objects and metallurgical development in the UIV and its neighbouring regions. Current data suggest that most of the objects dating to the Bronze Age found in the UIV region were probably imported from other places as indicated by their lead isotope composition, which is distinct from the mines and technical remains in the region. The only sample (sickle XY0019) that has similar isotopic data of the local mines and slags may in fact be ascribed to a later period, given that it is comprised of unalloyed copper with relatively high-arsenic concentration. Local copper smelting in the UIV emerged probably from the early first millennium BCE and accounted for a substantial proportion of the Iron Age objects discovered in the region. Several copper/bronze objects from the Chawuhu cemetery site in Hejing (ca 1000-500 BCE) have been revealed to have similar lead isotope ratios (Mei et al. 2002b), implying the potential exportation of metals from the UIV to neighbouring regions. In the meantime, a number of objects could still have been imported, though their origins are probably varied and distinct from the one(s) in the Bronze Age. The decrease of tin content in the Iron Age objects is suggestive of a tin shortage similar to that of several regions in the eastern Eurasian Steppe (Hsu et al. 2016), suggesting also inconsistent technological practises and material supplies between the two periods. 
It is worth pointing out that the research presented here is still preliminary, and some critical issues related to the UIV's early metallurgy are yet to be settled. For instance, research on the technological remains from Nulasai indicates the production of copper with significant lead and arsenical content (Mei and Li 1998); but confusingly, including the data reported here, very few objects have been identified to have such a compositional feature, and $\mathrm{Cu}-\mathrm{As}-\mathrm{Pb}$ alloys have only been identified among the objects discovered in the Hami region in eastern Xinjiang rather than the lli region (Mei et al. 2002a; Ling et al. 2008). Where and how were the metallurgical products from Nulasai used? Do the Cu-As-Pb objects in Hami imply an eastward circulation of this especial material? Perhaps it is, more likely that, unalloyed copper may have been produced in addition to the $\mathrm{Cu}-\mathrm{As}-\mathrm{Pb}$ "alloy" given the identical lead isotope ratios of Nulasai's slag and several objects with lead hardly detected. As might be expected, however, with the limitations of available evidence, these questions remain unclear. Further detailed investigations of the archaeological materials with adequate chronological and cultural context are necessary to advance our understanding of prehistoric metallurgy in the upper Ili Valley.

\section{Conclusion}

Compositional and metallographic analyses have revealed technological features of prehistoric copper/bronze objects discovered in the upper Ili Valley. Tin bronze was the dominant material used during the Bronze Age; but the use of tin seems to have decreased markedly during the Iron Age, as evidenced by the substantial proportion of unalloyed copper and clear drop in tin concentrations in the bronze samples examined. Most of the objects were manufactured by casting; while some cauldron samples show evidence of heating, and some tools/weapons received further hot or/and cold working for finishing. Lead isotope data show that most of the Bronze Age objects were likely imported;

conversely, local copper resources appear to have been exploited during the Iron Age, and many of the analysed objects could have been made locally using the local mineral resources. The changes of the material (alloys) and metal source(s) between the Bronze and Iron Ages in the upper Ili Valley imply various movements of objects, raw materials and related technical practises. This research is significant as a further contribution to our understanding of the mechanisms of the adoption of metallurgy in the region.

\subsection{Acknowledgements}

The authors would like to thank Mrs. Mei Guan and Mrs. Li Deng from the Ili Museum for their assistance during our investigation and sampling. Our thanks also go to Bo Wang, Wenying Li, Qiurong Ruan, Yanxiang Li, Jianjun Yu, Jianye Han and John Moffet for their supports and insightful comments. The authors have benefitted a lot from discussions with Professor Mark Pollard and other colleagues from the FLAME project and comments from two reviewers.

\subsection{Funding Information}

This work received financial support from the National Natural Science Foundation of China (51304020, 51474029), the National Administration for Cultural Heritage (2014220), the National Foundation of Social Sciences (12\&ZD151) and the Newton International Fellowship (NF160456). 


\section{Supplementary Material}

Supplementary data related to this article can be found at:

125202018679 MOESM1 ESM.docx $(8.4 \mathrm{mb})$

ESM 1 (DOCX $8560 \mathrm{~kb})$

125202018679 MOESM2 ESM.docx (16 kb)

ESM 2 (DOCX $16 \mathrm{~kb})$

\section{References}

Bray P, Cuénod A, Gosden C, Hommel P, Liu R, Pollard AM (2015) Form and flow: the 'karmic cycle' of copper. J Archaeol Sci 56:202-209. DOI: https://doi.org/10.1016/j.jas.2014.12.013.

Chen G (1987) Guanyu Xinjiang xinshiqi shidai wenhua de xin renshi (New understanding on the Neolithic cultures in Xinjiang). Kaogu 4:343-351 (in Chinese).

Chen G (2000) Xinjiang Yilihe liuyu wenhua chulun (An initial study of the Ili River Valley cultures). Ouya Xuekan 2:1-35 (in Chinese).

Chen K-T, Hiebert FT (1995) The late prehistory of Xinjiang in relation to its neighbors. J World Prehist 9:243-300.

Chen Z (2003) Xinjiang tongkuang leixing yu zhaokuang baqu (On the classification of copper deposits in Xinjiang and the prospecting areas). Xinjiang Geol 21:190-193 (in Chinese).

Cui JF, Rehren T, Lei Y, Cheng XL, Jiang J, Wu XH (2010) Western technical traditions of pottery making in Tang Dynasty China: chemical evidence from the Liquanfang Kiln site, Xi'an city. J Archaeol Sci 37:1502-1509. DOI: https://doi.org/10.1016/j.jas.2010.01.010.

Eaton ER, McKerrell H (1976) Near eastern alloying and some textual evidence for the early use of arsenical copper. World Archaeol 8(2):169-191.

Fitzgerald-Huber LG (1995) Qijia and Erlitou: the question of contacts with distant cultures. Early China 20:17-67.

Frachetti MD (2012) Multiregional emergence of mobile pastoralism and nonuniform institutional complexity across Eurasia. Curr Anthropol 53:2-38. DOI:

https://doi.org/10.1086/663692. 
Frachetti MD, Smith CE, Traub CM, Williams T (2017) Nomadic ecology shaped the highland geography of Asia's Silk Roads. Nature 543:193-198.

DOI: https://doi.org/10.1038/nature21696.

Gale NH, Stos-Gale Z (2000) Lead isotope analyses applied to provenance studies. In: Ciliberto E, Spoto $\mathrm{G}$ (eds) Modern analytical methods in art and archaeology, vol chemical analysis. Wiley: New York, Chichester, 503-584.

Gong G (1997) Xinjiang diqu zaoqi tongqi chulun (Brief discussion on the early copper objects from Xinjiang). Kaogu 9:7-20.

Grigor'ev FP, Ismagil R (1997) The cult bronzes of Semirechye of the Saka Period. Ancient Civilizations from Scythia to Siberia 3:241-252.

Guo W (1999) Qingtong fu zai ouya dalu de chuchuan (The early spread of the bronze cauldrons throughout the Eurasian continent). Ouya Xuekan 1:122-150 (in Chinese).

Guo W (2007) Di er qun qingtong tie fu yanjiu (A study of the second group of bronze/iron Fu cauldrons). Acta Archaeologica Sinica 1:61-96 (in Chinese).

Guo W (2012) Xinjiang shiqian wanqi shehui de kaoguxue yanjiu (Archaeological research on the societies of the late prehistoric Xinjiang). Shanghai Guji Press: Shanghai, China.

Han J (2007) Xinjiang de qingtong shidai he zaoqi tieqi shidai wenhua (Cultures in Xinjiang from the Bronze Age to the early Iron Age). Wenwu Press: Beijing, China (in Chinese).

Hsu Y-K, Bray PJ, Hommel P, Pollard AM, Rawson J (2016) Tracing the flows of copper and copper alloys in the early Iron Age societies of the eastern Eurasian Steppe. Antiquity 90:357-375. DOI: https://doi.org/10.15184/aqy.2016.22.

Hwang M-C (2014) Maixiang Zhongqi shidai (Toward an age of monumental bronze: importation and formation of bronze-making technology in China). Bulletin of the Institute of History and Philology Academia Sinica 85:575-678 (in Chinese).

Institute of Archaeology (IoA), CASS (1992) Zhongguo kaoguxue zhong tan shisi niandai shuju ji 1965-1991 (Data collection of the carbon dating in Chinese archaeology (1965-1991)). Wenwu Press: Beijing, China (in Chinese).

Jaang L (2015) The landscape of China's participation in the Bronze Age Eurasian Network. J World Prehist 28:179-213.

Jia PW, Betts A, Cong D, Jia X, Dupuy PD (2017) Adunqiaolu: new evidence for the Andronovo in Xinjiang, China. Antiquity 91:621-639. 
Li S (2005) Xibei yu zhongyuan zaoqi yetong ye de quyu tezheng ji jiaohu zuoyong (Regional characteristics and interaction of early metallurgy in northwest China and in the Central Plains). Acta Archaeologlca Sinica 3:239-275 (in Chinese).

Li X, Dang T (1995) Zhunge'er pendi zhouyuan diqu chutu tongqi chutan (Preliminary study of the copper objects unearthed from the areas surrounding the Dzungarian Basin). Xinjiang Wenwu 2:40-49 (in Chinese).

Linduff KM (2004) Metallurgy in ancient eastern Eurasia from the Urals to the Yellow River. Edwin Mellen Press: Lewiston, New York, USA.

Ling Y (2008) A study of metal technology during the first millennium BC in Xinjiang. University of Science and Technology Beijing:Beijing, China, China (in Chinese).

Ling Y, Mei J, Lu E (2008) Xinjiang yili diqu chutu shiqian tongqi de kexue fenxi (Scientific analysis of the prehistoric copper objects from the Ili region, Xinjiang). Ziran Kexueshi Yanjiu 27:359-369 (in Chinese).

Liu X, Guan B (2002) Xinjiang yili hegu shiqian kaoguxue de zhongyao shouhuo (On the major advances on the prehistorical archaeology in the Ili Valley, Xinjiang). Xiyu Yanjiu 4:106-108 (in Chinese).

Liu X, Li W (2012) Xinjiang shiqian kaoguxue yanjiu de xin jinzhan (Advances on the prehistorical archaeology in Xinjiang). Xinjiang Daxue Xuebao 1:1-7 (in Chinese).

Lu E (1995) Lun Xiniang kaoguxue yanjiuzhong cunzai de jige wenti (Several questions in the archaeological research in Xinjiang). Xinjiang Wenwu (2):70-77 (in Chinese).

Ma X, Zeng L, Zhou J, Shi W, Sui J (2017) Xi tianshan Awulale chengkuangdai xiduan tongkuang chengkuang zuoyong tezheng ji zhaokuang fangxiang (Prospecting direction and mineralization characteristics of copper in western Awulale metallogenic belt, western Tianshan Mountains). Xinjiang Geol 35:50-58 (in Chinese).

Marchella F, Zhang C, Liu W (2017) An overview of prehistoric archaeological research on Xinjiang by the western scholars. Xiyu Yanjiu 1:91-100 (in Chinese).

Mei J (2000) Copper and bronze metallurgy in late prehistoric Xinjiang : its cultural context and relationship with neighbouring regions. Archaeopress: Oxford, England.

Mei J, Colin S (1999) The existence of Andronova cultural influence in Xinjiang during the 2nd millennium BC. Antiquity 73:570.

Mei J, Colin S, Li X, Wang B (1998) A metallurgical study of early copper and bronze artefacts from Xinjiang. China Bull Metals Mus 30:1-22. 
Mei J, Hirao Y, Enomoto J, Li X, Wang B, Takahama S (2003) Xiniang zhunge'er pendi zhouyuan diqu chutu zaoqi tongqi de kexue fenxi (Scientific research on the early copper objects unearthed from the areas surrounding the Dzungarian Basin, Xinjiang). Gudai Wenming 2:230-240 (in Chinese).

Mei J, Li Y (1998) Xinjiang Nulasai gu tong kuangye yizhi yelian jishu chubu yanjiu (Preliminary research on the smelting technology at the Nulasai site, Xinjiang). Ziran Keuxeshi Yanjiu 17:289-295 (in Chinese).

Mei J, Ling Y, Chen K, Abdursul I, Li W, Hu X (2013) Xinjiang xiaohe mudi chutu bufen jinshuqi de chubu fenxi (A preliminary scientific analysis of some metal objects excavated from the Xiaohe cemetery in Xinjiang, China). Xiyu Yanjiu 1:39-49 (in Chinese).

Mei J, Liu G, Chang X (2002a) Xinjiang dongbu diqu chutu zaoqi tongqi de chubu fenxi he yanjiu (Preliminary study on the early copper objects from the eastern Xinjiang). Xiyu Yanjiu 2:1-10 (in Chinese).

Mei J, Lu E, Hirao Y (2002b) Xinjiang Chawuhu mudi chutu tongqi de chubu kexue fenxi (Initial scientific analysis on the copper objects from the Chawuhu cemetery). Xinjiang Wenwu (3/4):109-115 (in Chinese).

Mei J, Wang B, Li X (2005) Xinjiang chutu tongfu de chubu kexue fenxi (Preliminary scientific analysis of the copper Fu vessel from Xinjiang). Kaogy 4:78-84 (in Chinese).

Millward JA (2007) Eurasian crossroads: a history of Xinjiang. Columbia University Press: New York City, USA.

Molofsky L, Killick D, Ducea MN, Macovei M, Chesley JT, Ruiz J, Thibodeau A, Popescu GC (2014) A novel approach to lead isotope provenance studies of tin and bronze: applications to South African, Botswanan and Romanian artifacts. J Archaeol Sci 50:440-450.

Northover JP (1989) Properties and use of arsenic-copper alloys. In: Hauptmann A, Pernicka E, Wagner GA (eds) Old World Archaeometallurgy. Deutsches Bergbau-Museum: Bochum, 111118.

Peng K (1998) The Andronovo bronze artifacts discovered in Toquztara County in Ili, Xinjiang. In: Mair VH (ed) The Bronze Age and early Iron Age peoples of eastern Central Asia, vol 2. Institute for the Study of Man: Washington D. C., 573-580.

Pollard A, Bray P, Gosden C, Wilson A, Hamerow H (2015) Characterising copper-based metals in Britain in the first millennium AD: a preliminary quantification of metal flow and recycling. Antiquity 89:697-713. 
Qian W (2006) Xinjiang Hami diqu shiqian shiqi tongqi jiqi yu linjin diqu wenhua de guanxi (The prehistoric copper and bronze of Hami region in Xinjiang and their contexts of neighbouring cultures). Zhishi Chanquan Press: Beijing, China (in Chinese).

Ruan Q (2011) 2010 nian Xinjiang Yili he liuyu kaogu xin shouhuo (New achievements of archaeology in Xiniang's Ili reaches during 2010). Xiyu Yanjiu 2:130-133 (in Chinese).

Ruan Q (2012) Xiniang Yili Nileke Tangbale sayi mudi fajue jianbao (Brief report on the archaeological excavation at the Tangbale Sayi cemetery in Nileke, Yili, Xinjiang). Wenwu 5:13-22 (in Chinese).

Ruan Q (2013) Xinjiang faxian de an de luo nuo wo wenhua yicun yanjiu (recently identified Andronovo culture remains in Xinjiang). Xibu Kaogu 7:125-154 (in Chinese).

Shao H (2007) Xinjiang shiqian shiqi wenhua geju de yanjin jiqi yu zhoulin diqu wenhua de guanxi (The development of the prehistoric cultures in Xinjiang and the interaction with neighbour cultures). Jilin University, Changchun, China (in Chinese).

Sherratt S (2006) The trans-Eurasian exchange: the prehistory of Chinese relations with the west. In: Mair VH (ed) Contact and exchange in the ancient world, vol perspectives on the global past. University of Hawaii Press: Honolulu, 30-36.

Song Y (2009) Xinjiang qingtong shidai kaogu yanjiu xianzhuang pingshu (Review of the archaeological research on the Bronze Age Xinjiang). Xiyu Yanjiu 1:84-97 (in Chinese).

Wang B (1985a) Xinjiang qingtong shidai kaogu wenhua shixi (On the archaeological cultures of the Bronze Age Xinjiang). Xinjiang Shehui Kexue 4:50-61 (in Chinese).

Wang B (1987) Xiniang jin shinian faxian de yixie tongqi (Recent discoveries of copper objects in Xinjiang in last decade). Xinjiang Wenwu (1):45-51(in Chinese).

Wang B, Cheng Z (1989) Xinjiang Gongliu xian chutu yipi tongqi (Copper objects unearthed from Gongliu, Xinjiang). Wenwu (8)95-96. (in Chinese).

Wang F et al (2015) Spatio-temporal distribution and variability of cultural relics in the Ili River valley since 4000aBP. J Desert Res 35:1103-1112.

Wang M (1984) Nileke xian gutongkuang yizhi de diaocha (Investigation to the ancient copper mining site in Nileke). Zhongguo Kexuexue Nianjian 1:176-177 (in Chinese).

Wang M (1985b) Yili he liuyu sai ren wenhua chutan (Initial research on the Saka culture in the Ili River region). Xinjiang Shehui Kexue 1:59-65 (in Chinese). 
Wang M (1986) Nileke xian kaogu diaocha ji (Archaeological investigation in the Nileke County). Xinjiang Wenwu 1:16-19 (in Chinese).

Wen G (1980) Zhongguo gudai qingtong yu xikuang (Ancient bronze and tin deposits in China). Dizhi Pinglun 4:331-340 (in Chinese).

Xu Y, Chen Y, Li W, Fu A, Ma X, Gui D, Chen Y (2011) Distribution pattern of plant species diversity in the mountainous region of Ili River Valley, Xinjiang. Environ Monit Assess 177:681-694. DOI: https://doi.org/10.1007/s10661-010-1665-3.

Yang J, Shao H, Pan L (2016) Ouya caoyuan dongbu de jinshu zhilu (The metal road of the eastern Eurasian Stepp). Shanghai Guji Press, Shanghai, China. 
Supplementary Table S1. Background and finding information of the objects studied (Photo data source: Ili Museum)

\begin{tabular}{|c|c|c|c|c|c|}
\hline No. & Object & Origin & Remarks & Periodization/dating & Photo \\
\hline D0013 & Knife & $\begin{array}{l}\text { Tangjiale Memorial in } \\
\text { Xiinyuan }\end{array}$ & $\begin{array}{l}\text { donated chance finding; } \\
\text { Length: } 25.2 \mathrm{~cm}\end{array}$ & $\begin{array}{c}\text { Bronze Age/ca. } 14 \mathrm{C} \\
\text { BCE }\end{array}$ & \\
\hline XY0018 & Socketed axe & Gongliu County & $\begin{array}{l}\text { donated chance finding; } \\
\text { Length: } 14 \mathrm{~cm}\end{array}$ & $\begin{array}{c}\text { Bronze Age/ca. } 14 \mathrm{C} \\
\text { BCE }\end{array}$ & \\
\hline XY0019 & Sickle & Gongliu County & $\begin{array}{l}\text { donated chance finding; } \\
\text { Length: } 23 \mathrm{~cm}\end{array}$ & $\begin{array}{c}\text { Bronze Age/ca. } 10 \mathrm{C} \\
\text { BCE }\end{array}$ & \\
\hline
\end{tabular}




\begin{tabular}{|c|c|c|c|c|c|}
\hline No. & Object & Origin & Remarks & Periodization/dating & Photo \\
\hline XY0033 & Spear head & Nileke & $\begin{array}{l}\text { donated chance finding; } \\
\text { Length: } 14.8 \mathrm{~cm}\end{array}$ & $\begin{array}{c}\text { Bronze Age/ca. } 10 \mathrm{C} \\
\text { BCE }\end{array}$ & \\
\hline XY0072 & Sickle & Talede, Xinyuan County & $\begin{array}{l}\text { donated chance finding; } \\
\text { Length: } 27 \mathrm{~cm}\end{array}$ & $\begin{array}{c}\text { Bronze Age/ca. } 10 \mathrm{C} \\
\mathrm{BCE}\end{array}$ & \\
\hline XY0179 & Shaft-hole axe & Gongliu County & $\begin{array}{l}\text { donated chance finding; } \\
\text { Length: } 15.5 \mathrm{~cm}\end{array}$ & $\begin{array}{c}\text { Bronze Age/ca. } 14 \mathrm{C} \\
\text { BCE }\end{array}$ & \\
\hline
\end{tabular}




\begin{tabular}{|c|c|c|c|c|c|}
\hline No. & Object & Origin & Remarks & Periodization/dating & Photo \\
\hline XY0488 & Knife & $\begin{array}{l}\text { Nazituobie, Qiaolake Tiereke, } \\
\text { Tekesi County }\end{array}$ & $\begin{array}{l}\text { donated chance finding; } \\
\text { Length: } 11.1 \mathrm{~cm}\end{array}$ & $\begin{array}{l}\text { Bronze Age/ca. } 13 \mathrm{C} \\
\text { BCE }\end{array}$ & \\
\hline XY0489 & Socketed-axe & Tekesi County & $\begin{array}{l}\text { donated chance finding; } \\
\text { Length: } 10 \mathrm{~cm}\end{array}$ & $\begin{array}{c}\text { Bronze Age/ca. } 14 \mathrm{C} \\
\text { BCE }\end{array}$ & \\
\hline XY0493 & Knife & $\begin{array}{l}\text { Nazituobie, Qiaolake Tiereke, } \\
\text { Tekesi County }\end{array}$ & $\begin{array}{l}\text { donated chance finding; } \\
\text { Length: } 23.3 \mathrm{~cm}\end{array}$ & $\begin{array}{l}\text { Bronze Age/ca. 10C } \\
\text { BCE }\end{array}$ & \\
\hline XY0020 & Chisel & Gongliu County & $\begin{array}{l}\text { donated chance finding; } \\
\text { Length: } 16.7 \mathrm{~cm}\end{array}$ & Iron Age/ ca. 5-3 C BCE & \\
\hline
\end{tabular}









\begin{tabular}{|c|c|l|l|l|l|}
\hline No. & Object & \multicolumn{1}{|c|}{ Origin } & Remarks & Periodization/dating & Photo \\
\hline \multirow{2}{*}{ XY0048 } & Sword & $\begin{array}{l}\text { Xiaolake Tiereke, Tekesi } \\
\text { County }\end{array}$ & $\begin{array}{l}\text { donated chance finding; } \\
\text { Length: 28.5 cm }\end{array}$ & Iron Age/ ca. 8-5 C BCE \\
\hline & Altar/lamp & $\begin{array}{l}71 \text { Regiment in Xinyuan } \\
\text { County }\end{array}$ & $\begin{array}{l}\text { Excavated; } \\
\text { Broken fragments, } \\
\text { width: } 12 \mathrm{~cm}\end{array}$ & Iron Age/ ca. 5-3 C BCE & \\
\hline
\end{tabular}




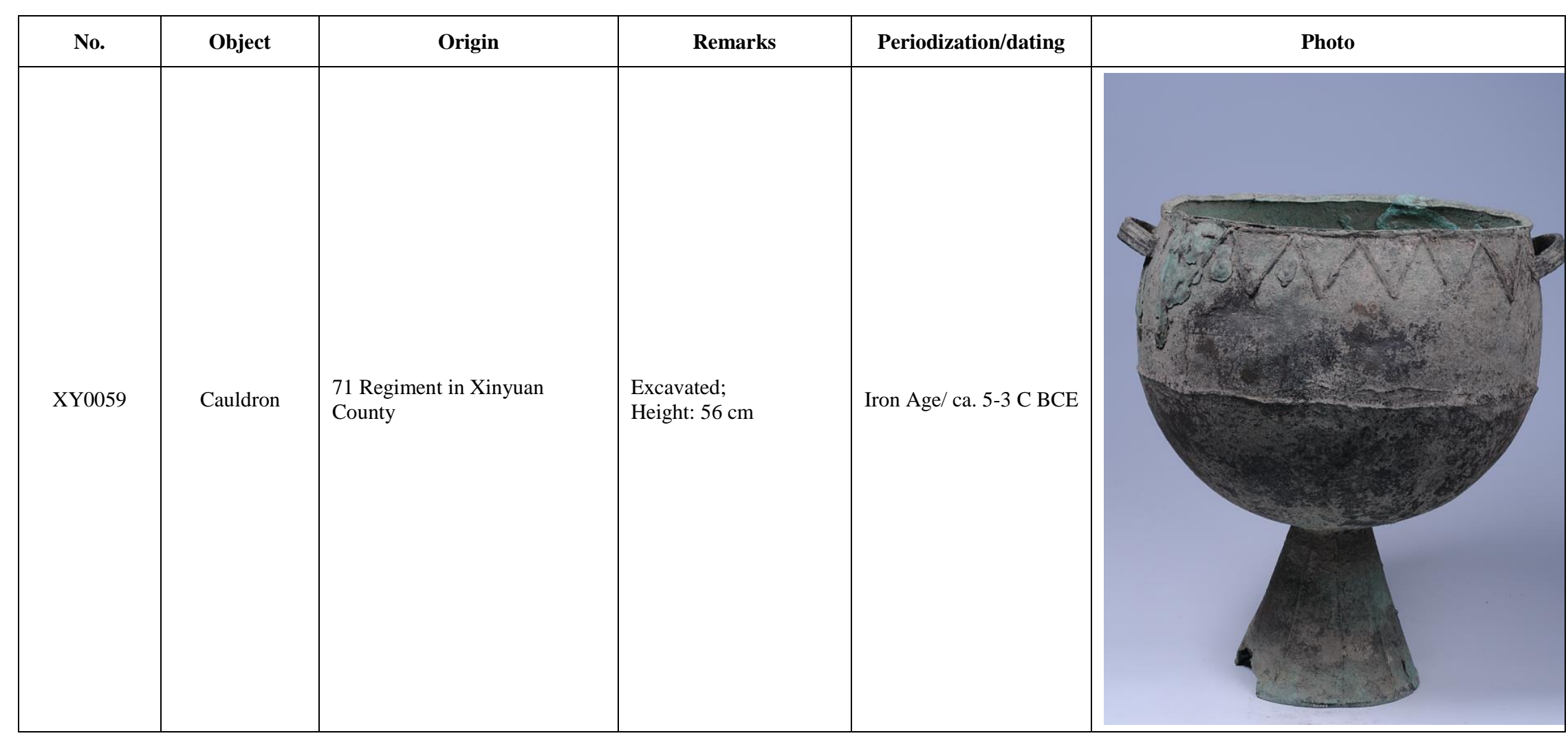




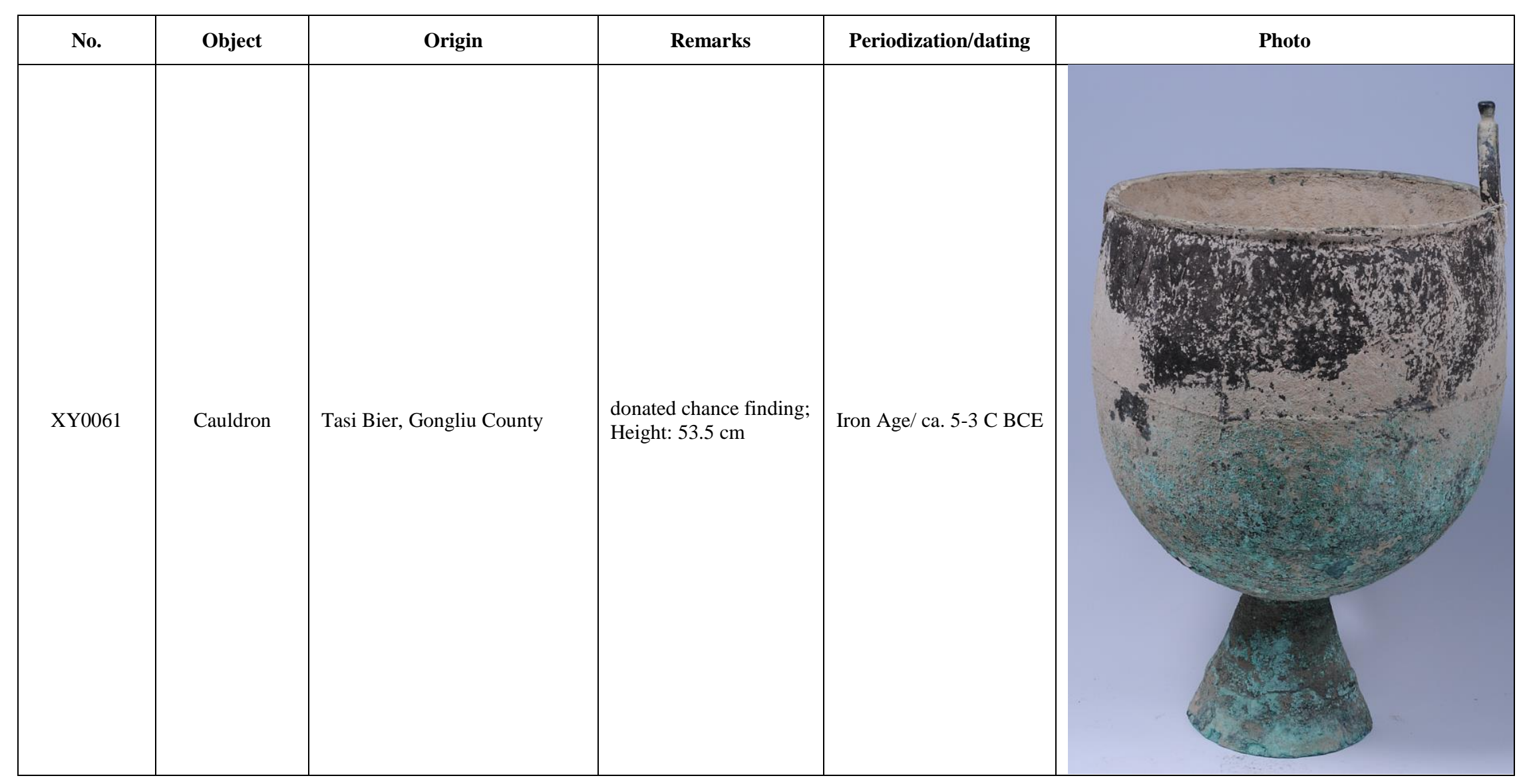




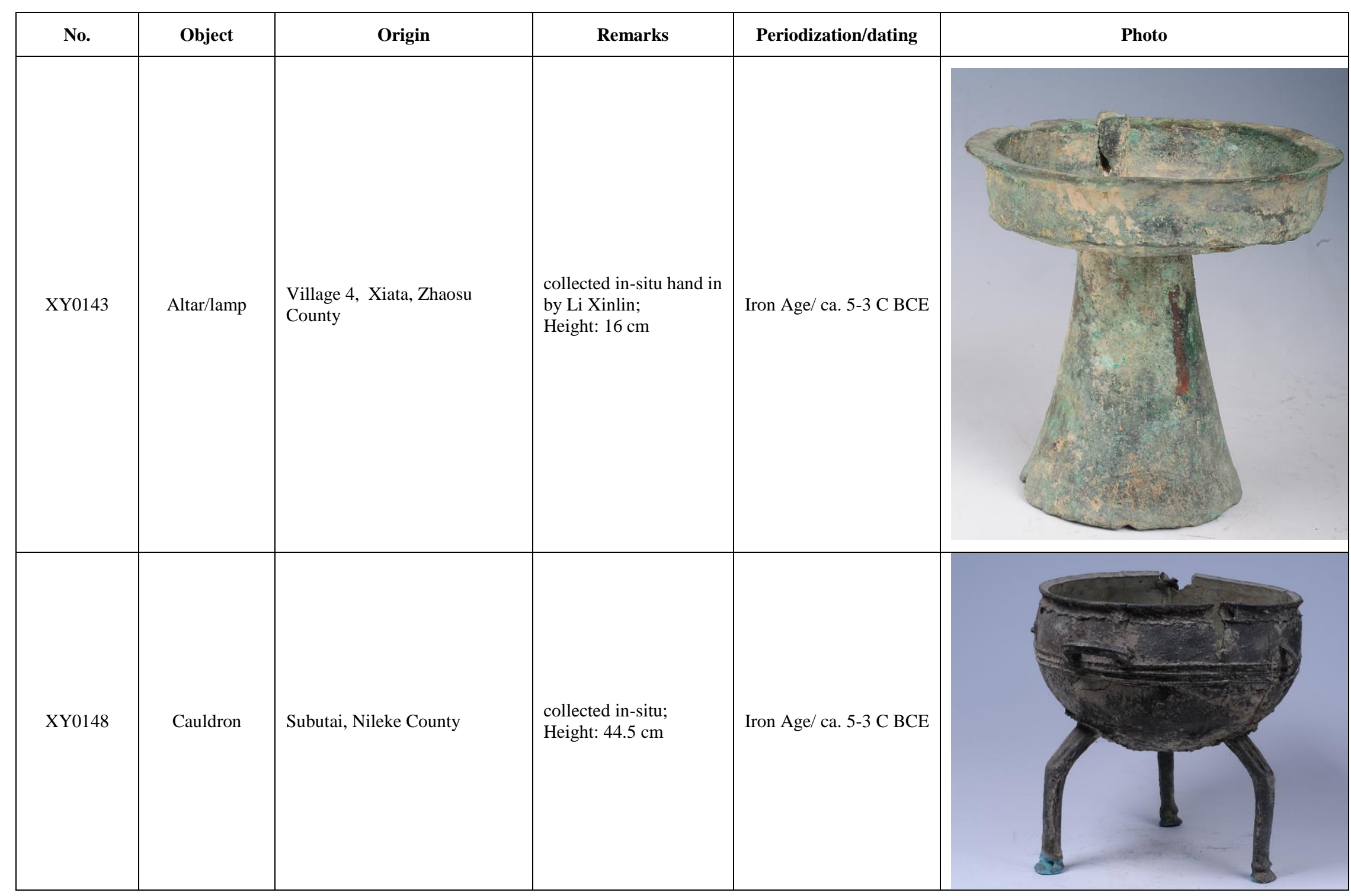









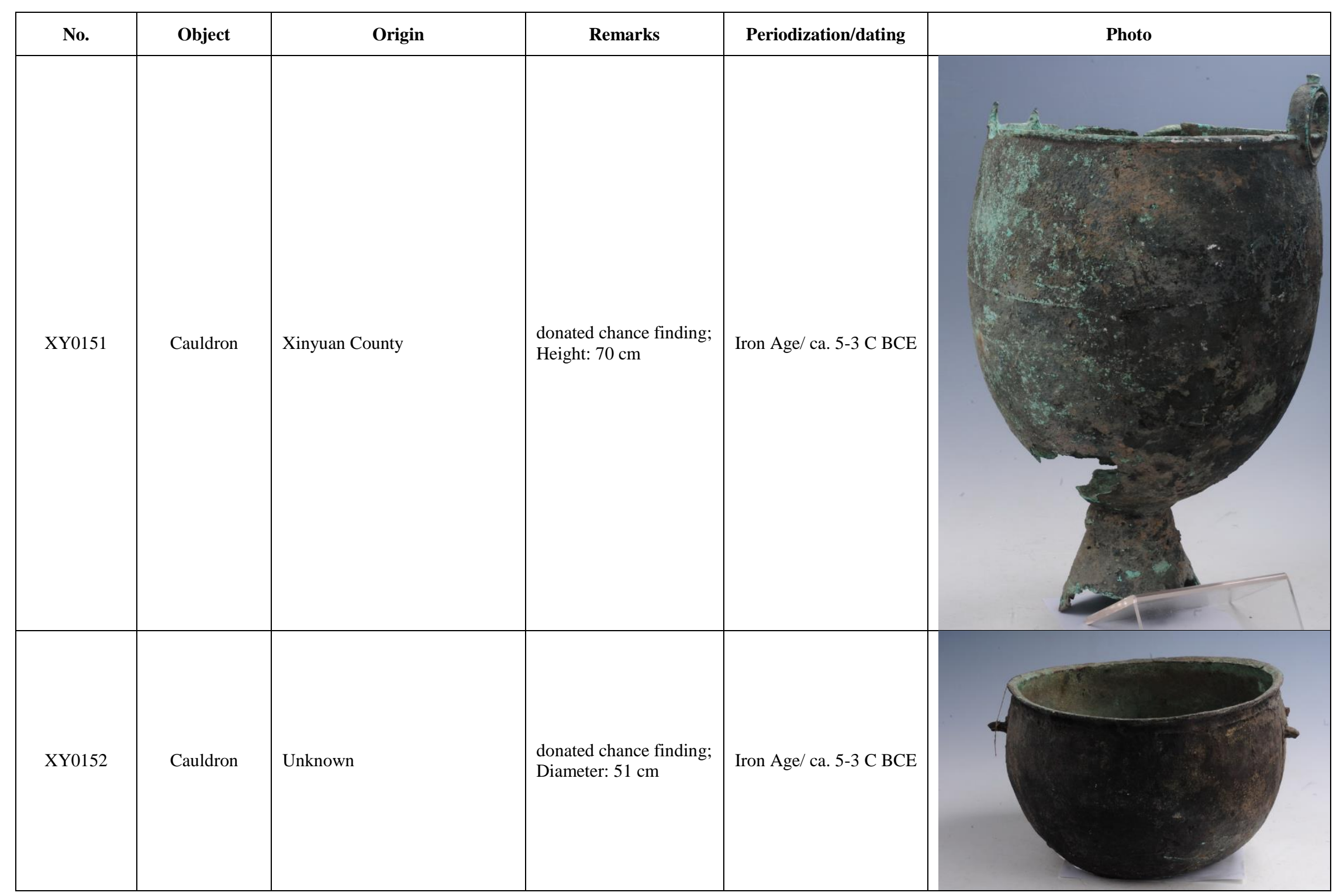














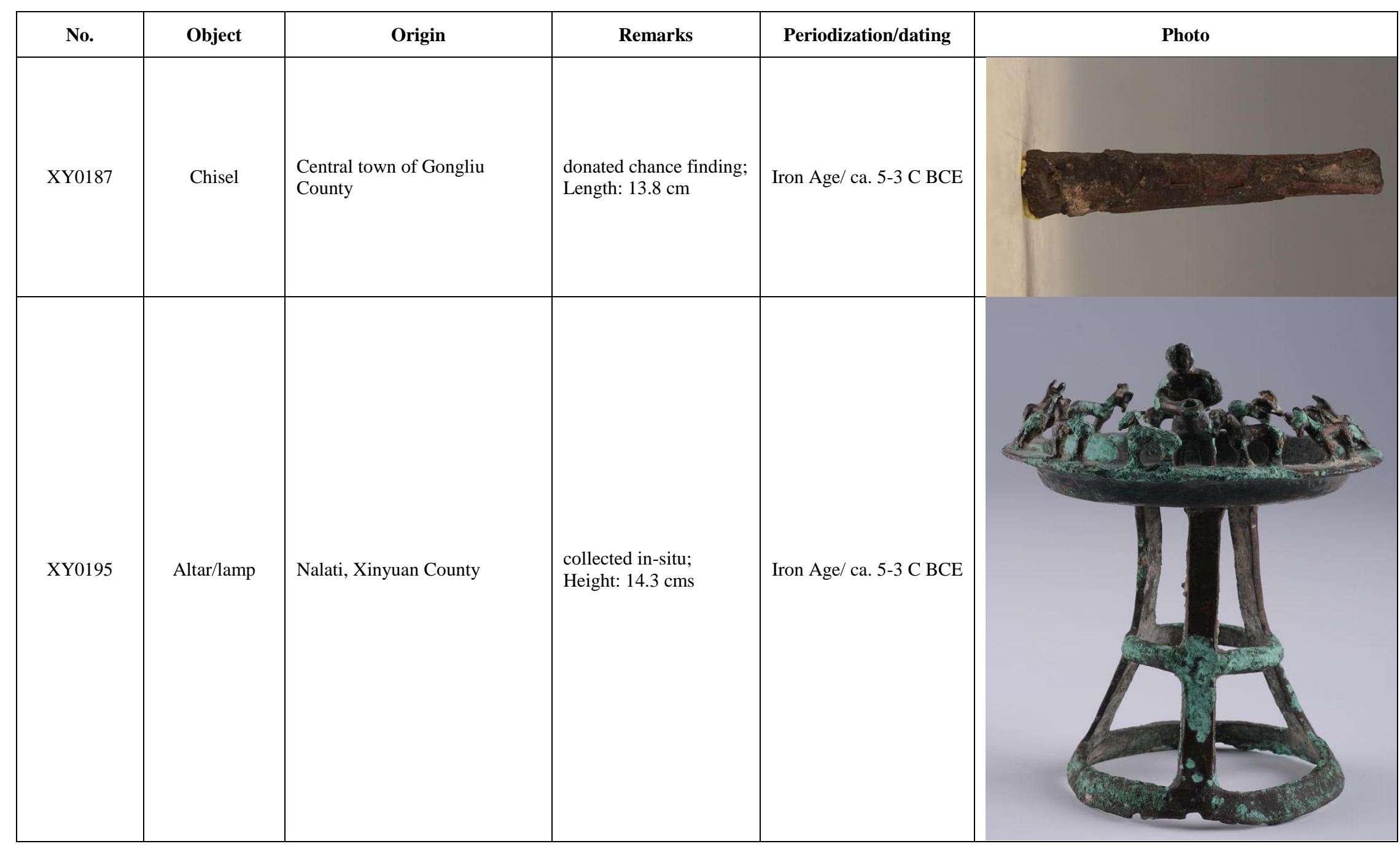




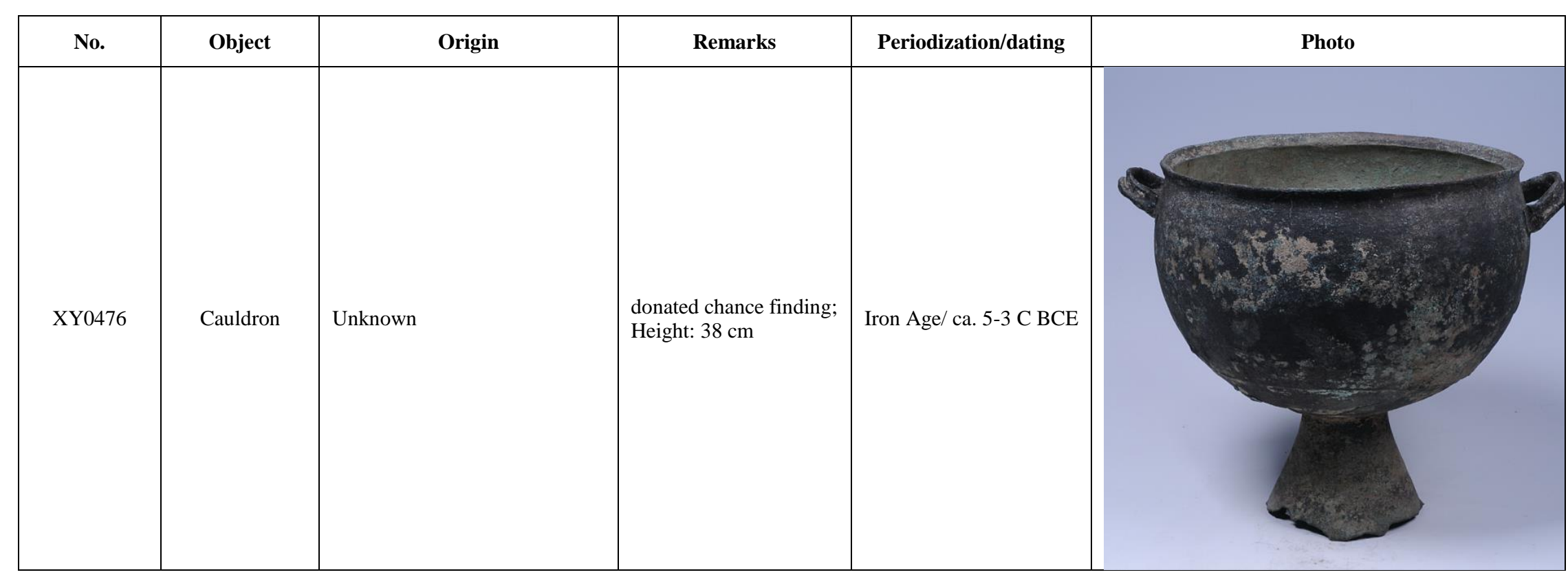




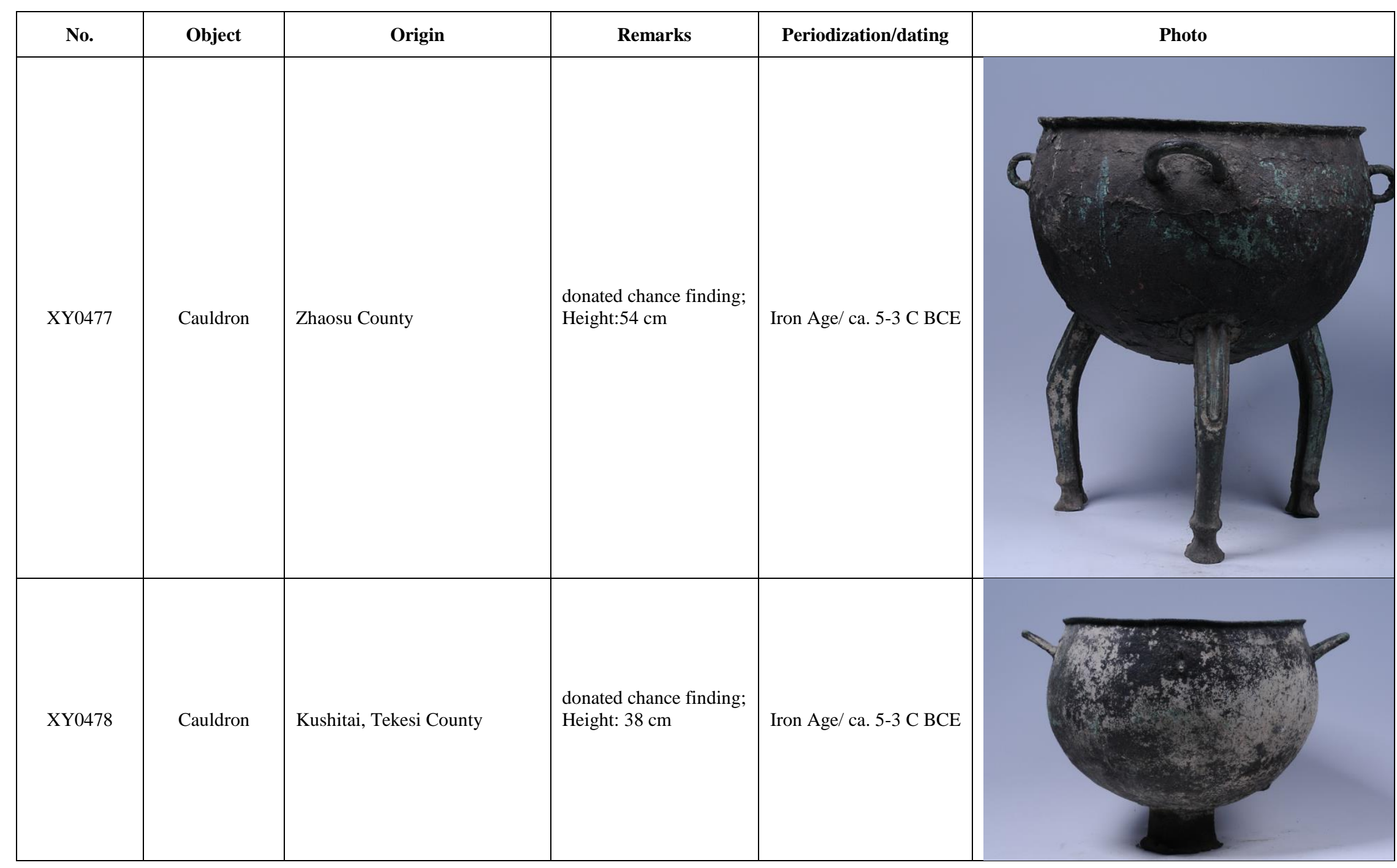




\begin{tabular}{|c|c|c|c|c|c|}
\hline No. & Object & Origin & Remarks & Periodization/dating & Photo \\
\hline XY0479 & Cauldron & Tekesi County & $\begin{array}{l}\text { donated chance finding; } \\
\text { Diameter: } 45 \mathrm{~cm}\end{array}$ & Iron Age/ ca. 5-3 C BCE & \\
\hline XY0657 & Mirror & Qiongkeke site, Nileke County & $\begin{array}{l}\text { Excavated; } \\
\text { Diameter: } 9 \mathrm{~cm}\end{array}$ & Iron Age/ca. 9-5 C BCE & \\
\hline
\end{tabular}


Supplementary Table S2. Lead isotopic data used for comparison in Figure 6

\begin{tabular}{|c|c|c|c|c|c|c|}
\hline Sample No. & $207 \mathrm{~Pb} / 206 \mathrm{~Pb}$ & $208 \mathrm{~Pb} / 206 \mathrm{~Pb}$ & $206 \mathrm{~Pb} / 204 \mathrm{~Pb}$ & $207 \mathrm{~Pb} / 204 \mathrm{~Pb}$ & Mineral & Origin \\
\hline NLS12 & 0.8594 & 2.0995 & 18.09 & 15.547 & Chalcocite & Awulale, Ili \\
\hline NLS15 & 0.8599 & 2.1002 & 18.061 & 15.531 & Chalcocite & Awulale, Ili \\
\hline NLS32 & 0.8624 & 2.1119 & 18.144 & 15.648 & Chalcocite & Awulale, Ili \\
\hline $109-26$ & 0.8974 & 2.1815 & 17.199 & 15.435 & Chalcopyrite & Awulale, Ili \\
\hline $109-27$ & 0.8343 & 2.0699 & 18.641 & 15.553 & Bornite & Awulale, Ili \\
\hline $109-31$ & 0.8535 & 2.0914 & 18.193 & 15.528 & Bornite & Awulale, Ili \\
\hline QBLK1 & 0.858 & 2.0957 & 18.099 & 15.529 & Chalcopyrite & Qiongkeke, Awulale, Ili \\
\hline QBLK2 & 0.8523 & 2.0835 & 18.179 & 15.495 & Chalcopyrite & Qiongkeke, Awulale, Ili \\
\hline QBLK3 & 0.8546 & 2.0941 & 18.16 & 15.521 & Chalcocite & Qiongkeke, Awulale, Ili \\
\hline QBLK33 & 0.8592 & 2.0825 & 18.403 & 15.503 & Chalcocite & Qiongkeke, Awulale, Ili \\
\hline QBLK4 & 0.8571 & 2.0921 & 18.077 & 15.494 & Chalcocite & Qiongkeke, Awulale, Ili \\
\hline QBLK5 & 0.8576 & 2.0931 & 18.058 & 15.487 & Chalcocite & Qiongkeke, Awulale, Ili \\
\hline QBLK6 & 0.8565 & 2.0912 & 18.096 & 15.501 & Chalcocite & Qiongkeke, Awulale, Ili \\
\hline QBLK7 & 0.85 & 2.0787 & 18.351 & 15.599 & Bornite & Qiongkeke, Awulale, Ili \\
\hline JS-10 & 0.8348 & 2.0937 & 18.736 & 15.641 & Chalcocite & Jiashi, north Tarim \\
\hline $\mathrm{JS}-11$ & 0.8416 & 2.0691 & 18.595 & 15.651 & Chalcocite & Jiashi, north Tarim \\
\hline JS-15 & 0.8471 & 2.0933 & 18.441 & 15.622 & Chalcocite & Jiashi, north Tarim \\
\hline JS-16 & 0.8416 & 2.0812 & 18.601 & 15.655 & Chalcocite & Jiashi, north Tarim \\
\hline JS-17 & 0.8437 & 2.0819 & 18.503 & 15.612 & Chalcocite & Jiashi, north Tarim \\
\hline JS-18 & 0.8412 & 2.0816 & 18.607 & 15.654 & Chalcocite & Jiashi, north Tarim \\
\hline JS-19 & 0.8409 & 2.0823 & 18.607 & 15.647 & Chalcocite & Jiashi, north Tarim \\
\hline JS-35 & 0.8449 & 2.0873 & 18.52 & 15.648 & Chalcocite & Jiashi, north Tarim \\
\hline $4-54$ & 0.8504 & 2.0875 & 18.654 & 15.864 & Chalcopyrite & Lamasu, Bortala \\
\hline E50 & 0.8641 & 2.1008 & 18.347 & 15.855 & Chalcopyrite & Lamasu, Bortala \\
\hline LMSY-10 & 0.8464 & 2.0849 & 18.437 & 15.605 & Chalcopyrite & Lamasu, Bortala \\
\hline LMSY-17 & 0.8534 & 2.0907 & 18.264 & 15.586 & Chalcopyrite & Lamasu, Bortala \\
\hline LMSY-3 & 0.8515 & 2.0875 & 18.309 & 15.59 & Chalcopyrite & Lamasu, Bortala \\
\hline LMSY-4 & 0.8257 & 2.0422 & 18.951 & 15.649 & Chalcopyrite & Lamasu, Bortala \\
\hline
\end{tabular}




\begin{tabular}{|c|c|c|c|c|c|c|}
\hline LMSY-5 & 0.8189 & 2.0239 & 19.1 & 15.641 & Chalcopyrite & Lamasu, Bortala \\
\hline LMSY-8 & 0.8011 & 1.9804 & 19.544 & 15.656 & Chalcopyrite & Lamasu, Bortala \\
\hline LMSY-9 & 0.8511 & 2.0819 & 18.302 & 15.575 & Chalcopyrite & Lamasu, Bortala \\
\hline K26 & 0.8564 & 2.0942 & 18.186 & 15.574 & Chalcopyrite & Kendenggaoer, Ili \\
\hline $\mathrm{K} 27$ & 0.8571 & 2.0974 & 18.205 & 15.604 & Chalcopyrite & Kendenggaoer, Ili \\
\hline K32 & 0.8571 & 2.0972 & 18.198 & 15.598 & Chalcopyrite & Kendenggaoer, Ili \\
\hline K36 & 0.8574 & 2.0976 & 18.192 & 15.598 & Chalcopyrite & Kendenggaoer, Ili \\
\hline K5 & 0.8656 & 2.1305 & 17.963 & 15.549 & Chalcopyrite & Kendenggaoer, Ili \\
\hline 2240 & 0.8603 & 2.104 & 18.135 & 15.601 & Ore & Nulasai, Nileke, Ili \\
\hline 2298 & 0.8597 & 2.1003 & 18.095 & 15.556 & Ore & Nulasai, Nileke, Ili \\
\hline 2299 & 0.8597 & 2.1006 & 18.099 & 15.56 & Ore & Nulasai, Nileke, Ili \\
\hline $122-1$ & 0.8606 & 2.1054 & 18.151 & 15.625 & Ingot & Nulasai, Nileke, Ili \\
\hline $122-2$ & 0.8605 & 2.1049 & 18.148 & 15.616 & Ingot & Nulasai, Nileke, Ili \\
\hline 121 & 0.8605 & 2.1049 & 18.096 & 15.619 & Ingot & Nulasai, Nileke, Ili \\
\hline 60 & 0.8595 & 2.1001 & 18.098 & 15.556 & Slag & Nulasai, Nileke, Ili \\
\hline 65 & 0.8597 & 2.1004 & 18.098 & 15.556 & Slag & Nulasai, Nileke, Ili \\
\hline 66 & 0.8596 & 2.1002 & 18.092 & 15.552 & Slag & Nulasai, Nileke, Ili \\
\hline 67 & 0.8596 & 2.1002 & 18.09 & 15.55 & Slag & Nulasai, Nileke, Ili \\
\hline 68 & 0.8597 & 2.1004 & 18.096 & 15.557 & Slag & Nulasai, Nileke, Ili \\
\hline 102 & 0.8607 & 2.1053 & 18.146 & 15.618 & Ingot & Nulasai, Nileke, Ili \\
\hline 940155 & 0.861501 & 2.10294 & 18.4823 & 15.293 & Slag & Nulasai, Nileke, Ili \\
\hline 940156 & 0.865893 & 2.1282 & 18.3312 & 15.873 & Ore & Nulasai, Nileke, Ili \\
\hline 940157 & 0.861576 & 2.10336 & 18.5443 & 15.977 & Slag & Nulasai, Nileke, Ili \\
\hline 940158 & 0.862106 & 2.10368 & 18.405 & 15.867 & Matte & Nulasai, Nileke, Ili \\
\hline
\end{tabular}

